\title{
Apuntes sobre el comercio exterior y la moneda durante la época del emperador Justiniano (527-565)
}

\author{
Notes on Foreign Trade and Currency During the Period \\ of The Justinian Emperor (527-565)
}

\author{
Henry Daniel Vera Ramírez \\ Universidad Minuto de Dios, Bogotá D.C - Colombia \\ http://orcid.org/0000-0002-3977-3073 \\ hveraramire@uniminuto.edu.co
}

Fecha de recepción: 12 de julio de 2017

Fecha de aceptación: 30 de septiembre de 2017

Sugerencia de citación: Vera Ramírez, H.D. (2018). Apuntes sobre el comercio

exterior y la moneda durante la época del emperador Justiniano (527-565).

tiempo\&economía, 5(1), 57-99, doi: http://dx.doi.org/10.21789/24222704.1272

\section{RESUMEN}

Este artículo presenta un análisis histórico del desarrollo del comercio y de la moneda, en el periodo comprendido entre la llegada al poder de Justiniano (527-565) y su declive. El objetivo es entender las razones por las cuales este periodo se caracterizó por un aumento significativo del flujo comercial, en contraposición con el descenso en el comercio que se generó sobre todo a partir de la escisión del Imperio Romano en el siglo IV de nuestra era y en el evento capital que significó el traslado del Imperio romano a la ciudad de Bizancio. Paralelo a este desarrollo histórico se plantea el papel de la moneda en el tránsito de las Economías pre-capitalistas a las capitalistas, como elemento subsidiario de la actividad comercial.

Palabras clave: Comercio internacional, Moneda, imperio Bizantino, Justiniano, historia económica

Códigos JEL: B40, F10 


\section{ABSTRACT}

This article presents a historical analysis of the development of trade and currency, in the period between the rise to power of Justinian (527-565) and its decline. The objective is to understand the reasons why this period was characterized by a significant increase in commercial flow, as opposed to the decline in trade that was generated mainly from the split of the Roman Empire in the fourth century of our era and in the capital event that meant the transfer of the Roman Empire to the city of Byzantium. Parallel to this historical development is the role of currency in the transition from pre-capitalist to capitalist economies, as a subsidiary element of commercial activity.

Keywords: International trade, Money, Byzantine Empire, Justinian, Economic History JEL Codes: B40, F10 


\section{Introducción}

Una de las explicaciones más complejas de la importancia de la moneda en el tránsito de las economías pre-capitalistas a las capitalistas, la encontramos en los planteamientos de Marx $(1974,1997)$, teoría que es subsidiaria de la actividad comercial, es decir la actividad comercial es primordial para el desarrollo de la moneda. A pesar de ello, autores como Pirenne (1983) y Pounds (1987) han sostenido la importancia del comercio en periodos de desarrollo anteriores a la explicación marxista, haciendo énfasis en el descenso en el comercio que se generó sobre todo a partir de la escisión del Imperio Romano en el siglo IV de nuestra era y en las implicaciones que tuvo el traslado del Imperio romano a la ciudad de Bizancio.

En el presente documento exponemos, en principio, algunos elementos relacionados con la importancia de la historia económica desde Bergier (1963, 1973), para contextualizar los ejercicios de cuantificación propuestos más adelante. Luego hacemos una breve exposición que da cuenta de las características sociales de la época de florecimiento del Imperio bizantino; posteriormente explicamos las características del comercio, la moneda y de la Economía en General, durante el Imperio bizantino para luego establecer una relación causal entre las reformas llevadas a cabo por Justiniano, en términos de la consolidación definitiva del Cristianismo, del cuerpo de doctrina jurídica y su relación con la moneda y el comercio. A continuación, presentamos un análisis cuantitativo de algunos productos clave en el desarrollo de dicho comercio. Para ello tendremos en cuenta los planteamientos de Marx (1974, 1997), Baynes (2014), Herrin (2009), Brehier (1969), Ostrogorsky (1963), McCormick (2001) y el trabajo capital de Laiou y Morrison (2007) y Morrison (2012). Finalmente abordamos las condiciones del comercio y del manejo de la moneda durante la época de Justiniano. Estos elementos podrán sostener una hipótesis clave: la época de Justiniano puede considerarse como una época de florecimiento económico, expansión comercial y equilibrio monetario, pero a su vez encausada hacía guerras insostenibles por el deseo de recuperación territorial de un imperio ya fenecido.

Con respecto al primer aspecto, la historia económica según Bergier (1973) ha sufrido una renovación en el sentido del uso de su método y de la búsqueda de una solución interpretativa a una problemática cuantitativa: la ausencia de datos. Ha habido un resurgimiento de la historia económica sobre todo desde la mitad del siglo pasado, siendo la interpretación marxista de la historia y las profundas transformaciones de las estructuras de la sociedad industrial, los ámbitos de estudio más relevantes que se han acompañado a su vez con nuevos hallazgos arqueológicos. A este respecto los aportes de McCormick (2001) son muy importantes, ya que recupera el estudio del comercio durante años, a través de hallazgos cuantitativos y actualizando la importancia del transporte marítimo para el comercio. En este sentido, el análisis de McCormick, no estaría alejado del de Bergier:

...al mismo tiempo existen economistas que sentían la necesidad de no detenerse a los niveles de abstracción de la escuela clásica y de ofrecer a las propias especulaciones una materia más económica observable en el pasado (énfasis añadido). (Bergier, 1973, p. 3)

La teoría económica clásica parece incapaz de analizar a las sociedades pre o proto-capitalistas, razón de más para la búsqueda de interpretaciones de los eventos económicos del pasado a la luz de realidades y no de abstracciones. Sin embargo, la Economía no puede constituirse sólo en disciplina soporte, en lo referente a la historia económica ya que en muchos casos, 
al mal uso de técnicas investigativas se ha sumado una degeneración en interpretaciones parciales bajo marcos referenciales inocuos e irrelevantes. El mismo autor señala por ejemplo la importancia de la Econometría, que permite la construcción de modelos dinámicos con base en datos cuantitativos'.

La historia económica es entonces, según Barry E. Supple (citado por Bergier), un diálogo entre ciertos acercamientos conceptuales que debe tener en cuenta los elementos cuantitativos por cuanto estos definen la cotidianidad de los eventos económicos. Para citar un ejemplo:

En la Economía preindustrial y pre-capitalista de la época medieval, las ferias de Ginebra se dedican específicamente a los cambios a larga distancia de las mercancías de lujo (especias, sedas, etc.), principal objetivo de los tráficos a distancia en aquella época. Ellas tenían esta función, aunque lejos de las vías marítimas porque el alto costo de los transportes terrestres incide significativamente sobre la formación del precio de tales mercancías, de valor elevado y escaso volumen, y está compensado por la más pequeña inmovilidad de los capitales. Pero cuando la demanda y la oferta de estos productos sufre modificaciones y adquiere mayor importancia la de mercancía más voluminosa, el mercado Ginebrino declina. (Bergier, 1973, p. 9)

Hay otra interpretación que trata el mismo hecho, que considera por ejemplo que el comercio de esta ciudad no estaba sostenido realmente por los habitantes de la ciudad, los cuales no tienen mentalidad mercantil, lo que produce posteriormente un empobrecimiento de la población en beneficio de la ciudad de Lione cercana a Ginebra. Pero, ¿cómo saber con datos realistas la afectación comercial de la ciudad de Ginebra en beneficio de la ciudad de Lione? El debate sobre la necesidad de cuantificar los aspectos históricos, en términos de la ciencia histórica para el análisis de los hechos del pasado y el uso de la techne está abierto.

La relación entre Economía e Historia no deja de ser interesante, por cuanto genera fuertes contradicciones entre posturas frente a los orígenes de los movimientos mercantiles y la importancia singular del dinero. Según Bergier (1963), existen dos teorías bien definidas, una de corte economicista que considera que el origen del capitalismo ocurre en el Renacimiento en el siglo xvı, con factores como la inflación monetaria, la revolución de los precios, la influencia de las ferias comerciales y los inicios de una producción pre-industrial. En este terreno, encontramos los análisis de Marx, Sombart, Weber y Bucher.

En el comercio a partir del año 300, se puede observar un nivel de sofisticación no antes advertido y que McCormick expresa a través del análisis de una estructura portuaria, naval e impositiva que generó relevantes ganancias al Estado y especialmente al Estado bizantino. Pero habrá otra tendencia más histórica que considera que el origen del capitalismo se remontará a los siglos XI y xII, que debe tener en cuenta elementos como la explosión demográfica, la influencia de los comerciantes y de los prestamistas usureros. En esta segunda visión estarían autores como Pirenne, Dopsch, Sayous y Hauser. Pero probablemente esa concentración de

1 En este sentido la historia cuantitativa término usado recientemente, ha dado lugar a polémicas en Francia desde los años setenta, ya que en principio el concepto se refirió, según Jean Marczeweski al simple cálculo del ingreso nacional en países en series de tiempo históricas; por otro lado se encuentran autores como Pierre Chaunu que realiza análisis de lo que se denomina historia in serie y los enfoques de análisis de institucionalistas como Douglas North, que a pesar de ello ha denunciado algunos fracasos de la nueva historiografía económica debidos a la falta de certeza de los modelos econométricos. Robert Fogel en Estados Unidos, pueden ubicarse en este rango. 
los economistas en la modernidad tenga que ver específicamente con el hecho de que la Economía es una ciencia hija de la modernidad, nomotética, en el sentido de Wallerstein (2006), que le impide poder acercarse a otros periodos históricos no sin cierto recelo de fracasar ante la ausencia de datos empíricos.

Los economistas se han limitado en su observación, al campo de la historia reciente, donde los instrumentos de medida no cometen errores. El renacimiento les ha parecido el umbral lejano más allá del cual la Edad Media les parece prehistórica y casi legendaria. Y los historiadores que, por el contrario, descubren al mismo tiempo con entusiasmo, los aspectos apasionantes de la historia medieval tratan de encontrar allí la cuna de casi todos los fenómenos contemporáneos. (Bergier, 1963, pp. 6-7)

Si los economistas, como afirma Bergier, no van más allá del Renacimiento, la Edad Media, resulta siendo atacada y reducida a esquemas funcionales de actores sociales arquetípicos: el señor feudal, el campesino o siervo, el monje, el monarca y el mercader, generando un espacio de análisis limitado que impide observar el germen o si se quiere el caldo de cultivo de las posteriores sociedades proto-industriales e industriales. Y en esta evolución de los estudios de la Edad Media, el estudio -mucho más concentrado- del desarrollo del Imperio bizantino va a tener una importancia fundamental no sólo como representante portador de la cultura occidental, sino en el desarrollo ulterior del comercio, que va a pasar de un comercio de bienes suntuarios mucho más exclusivo y cerrado a uno más voluminoso que permitirá el advenimiento de la clase burguesa.

\section{Contexto histórico Siglo III}

En este desarrollo histórico debemos tener en cuenta que en el siglo II de nuestra era, el mundo estaba dominado por cuatro grandes imperios: el Imperio romano, cuya extensión comprendía terrenos que se ubicaban desde la península ibérica hasta los límites del oriente medio; el Imperio chino que se dividía en tres Estados independientes con la subsecuente desaparición del reinado de los Han (220); por su parte en Persia el Imperio sasánida (226-651) se extendía hasta la India, tratando de sobrevivir a los ataques constantes del Imperio romano. En la India, el imperio Kushan (105-250), es sustituido por el Gupta (320-550), para ser poco más adelante destruido por los hunos blancos. La existencia de estos imperios, favoreció de manera significativa el intercambio entre Oriente y Occidente y especialmente el comercio entre productos de los imperios cercanos al Pacífico y de los imperios cercanos al Atlántico.

Pero esta relación no solo consistió en un intercambio de mercancías, sino que significó una transformación sustancial en los modos de pensar que permitirían -en cierto sentidola configuración de un nuevo mundo a partir de la interacción de pueblos que se alineaban bajo los diferentes imperios y que iban a generar una fuerte presión que tendría como resultado el desmembramiento del Imperio de Occidente. Y servirá además, para sostener refutar o analizar como tesis básica que el comercio entre imperios significó una fuente de riqueza anterior a la Edad Media, por cuanto constituía una práctica fundamental en la obtención de beneficios para mercaderes y compradores y para el mismo Estado a través del cobro de tasas impositivas. 
La transformación sustancial en el modo de producción que llegará a través de los feudos significó el detrimento de la actividad comercial. Por tal razón, se comparte la idea de que el retroceso que implicó para la Edad Media la vuelta a un sistema basado en la actividad agrícola como lo sostienen Pirenne (1983) y Pounds (1987), va a ver compensada por la actividad comercial ejercida principalmente por el Imperio Romano de Oriente o el denominado Imperio bizantino $^{2}$. El objetivo fundamental es analizar los principales procesos históricos que permitieron que se desarrollará la actividad comercial en el Imperio bizantino, enfocando el análisis en los años 483-565, periodo en el cual el emperador Justiniano I, detentó el poder ${ }^{3}$. En principio se realizará un análisis de las principales características económicas del periodo que va desde la caída del Imperio romano de Occidente en el año 476 y de la Alta Edad Media, seguido de un breve análisis de las características que podrían definir, en términos muy generales, al Imperio bizantino. En una tercera parte, se concentra el análisis en el Imperio bajo Justiniano (483-565), seguido de un apartado teórico sobre los principales postulados de los planteamientos de Marx $(1974,1997)$. Finalmente se hará una descripción de la actividad comercial y el uso de la moneda durante el periodo del emperador a la luz de los planteamientos teóricos de la explicación clásica del comercio internacional.

\section{Condiciones previas al advenimiento del Imperio Romano de Oriente}

El imperio Romano permeó profundamente al mediterráneo. Para McCormick (2001), los datos arqueológicos apuntan a un grado sin precedentes en el desarrollo de la economía inter-regional que se acompañó de una unificación política y cultural. El Imperio romano, atravesó profundas crisis políticas internas que determinarían, aunadas éstas con los constantes ataques de las tribus bárbaras del Norte, en su declive y en lo que histórica y erróneamente se denominó caída del Imperio romano (476). Entre las múltiples explicaciones que se han dado para poder entender esta decadencia y caída se encuentran aquellas que clasifican sus causas desde argumentos políticos y migratorios, hasta sociales y económicos incluyendo sus posibles combinaciones. En las causas histórico-económicas, por ejemplo, autores como Pirenne (1983) y Pounds (1987), consideran como elemento básico la pérdida sustancial en el intercambio comercial que como consecuencia generó la vuelta a un estadio dependiente de la agricultura, que determinará un nuevo modo de producción: el feudal.

Una de las explicaciones más ampliamente divulgadas y aceptadas en un momento dado sobre la decadencia del Imperio romano se basaba en la destrucción del comercio. El Imperio, se decía, se mantenía unido por caminos y, sobre todo, por sus rutas marítimas, por las que discurría un flujo continuo de productos. (Pounds, 1987, p. 37)

2 Nombre que como afirma Herrin (2009, p. 18), no le viene bien y que ha adquirido una connotación negativa desde Gibbon (2010).

3 Si bien, en principio parecería anacrónico analizar una situación histórica de intercambio comercial a la luz de una teoría mucho más moderna, no deja de servirse la historiografía de nuevas herramientas para analizar los eventos del pasado en procura de desenvolver el hilo de los hechos y más cuando el medievo pareciese haber confinado a niveles muy bajos el comercio -afirmación que puede ser susceptible de debate- hasta su resurrección en el siglo XII y XIII. 
Se debe analizar el hecho de que el transporte de mercancías vía terrestre era lento y muy costoso. Diocleciano (244-211), por ejemplo, prescribió el edicto sobre precios, que en uno de sus apartados contenía como mecanismo impositivo el siguiente cálculo: el precio del transporte de la mercancía correspondería a un rubro de 20 denarios, por cada $1 / 2$ Tonelada, que recorriera 300 Millas $^{4}$. De esta forma si un mercader transportase, por ejemplo, trigo desde alguna parte del imperio a Roma, los costos del transporte terrestre resultaban muy altos, por no decir que impagables. Como apunta McCormick (2001), el movimiento de bienes por tierra era mucho más costoso que por mar; en el edicto de precios de Diocleciano, se confirma la clásica observación de que costaba menos transportar un grano de un extremo del Mediterráneo al otro que cargarlo 75 millas (McCormick, 2001, p. 83). Por esta razón, el transporte terrestre era usado sobre todo para el tránsito de mercancías lujosas, siendo el transporte marítimo el más usual sin que la relación entre toneladas/millas de transporte por mar fuese relativamente alta.

La importancia económica del movimiento a través del mar de millones de fanegas de grano fiscal cada año era innegable. La transferencia de alimentos permitía el cobro de impuestos que benefició sobre todo a las capitales a la corte y al ejército. Los barcos además, eran subsidiados por el Estado, lo que propició que el sistema naval-comercial, tuviese un desarrollo considerable a partir del siglo IV, en especial de aquellos barcos que traían grano a Roma. La existencia de emperadores, era sinónimo de abundancia y altos precios, lo que impelía a los comerciantes a buscar bienes suntuosos y lujosos para las cortes (McCormick, 2001, p. 86). Por otro lado, la navegación se consideraba estacional, estando los barcos atracados durante la tercera parte del año sobre todo por temas climáticos y el resto del tiempo, se consideraba viable para navegarlo 5 . Con la necesidad de abastecer a Roma se creó la agremiación de los dueños de buques que se organizarían en corporaciones denominadas navicularii, con un alcance realmente limitado en términos de su influencia en poder preservar el destino imperial. La Biblioteca Jurídica Virtual (s.f) de la Universidad Nacional Autónoma de México analiza las normas que han regulado históricamente el Derecho mercantil; considera que el comercio como actividad económica precedió la aparición del conjunto de normas que lo regulan. Con respecto a la Edad Antigua, el tránsito a sociedades más organizadas a través de una división del trabajo tuvo como consecuencia el paso de un comercio de consumo a uno mucho más complejo que introdujo el uso de un medio de cambio que pudiese generar una ganancia o beneficio. El uso de la moneda como medio de cambio resulta ser básico para este desarrollo. Va a ser en el Imperio romano donde se regula el comercio a través de normas del Derecho Civil ${ }^{6}$.

4 El edicto sobre precios del año 302 intentó remediar la situación de descalabro monetario, así como el de la inflación por medio de la fijación de precios máximos de mercado y de topes a nivel salarial, a la vez que se emitía nueva moneda. Estas iniciativas no tuvieron el desenlace esperado ya que el edicto se ignoró y la inflación era ya insostenible. Ver Pounds (1987, p. 49).

5 En la época estival, los barcos alcanzaban a cargar máximo 200 toneladas (Pounds, 1987).

6 Los aspectos relevantes que determinan estas normas son las siguientes: existían unas normas denominadas sustantivas, entre las que se encontraban la echazón por avería, que consistía en la distribución equitativa de las pérdidas de individuos que tuviesen interés particular en las mercancías de cualquier nave que tuviese que arrojar las mercancías al mar para salvar a la tripulación. Este documento era regulado por la Lex Rodhia de lactu. El phoenus nauticum o préstamo a la gruesa, correspondía a un contrato por medio del cual una de las partes estaba obligada a entregar un valor en dinero a otra que debía devolver al otro la cantidad pactada más unos intereses cuando la mercancía fuese devuelta de manera tal que las mercancías 
No es posible calcular el flujo de comercio en la época del imperio romano, pero lo que se considera seguro es que tuvo un declive en la época en que el imperio terminó, flujo que viene a restablecerse en los albores del renacimiento. Siempre se ha caracterizado de igual manera al Imperio por el gran circuito de caminos que permitía los desplazamientos en el mismo. Como el transporte terrestre resultaba complicado por el pago de peajes, a muchos mercaderes les era prohibido el uso de los mismos, sobre todo en las zonas provinciales y en el denominado cursus publicus. Pounds (1987), sostiene que el comercio terrestre quedaba restringido por tanto principalmente a los géneros más valiosos.

Los principales productos del comercio mediterráneo eran los granos -sin duda, el más importante en cuanto a volumen, seguido del aceite de oliva y quizá el vino. Egipto y el norte de África eran los principales productores de trigo. El aceite parece haber provenido principalmente del sur de España. A partir del siglo III, el volumen de aceite español importado por Roma, empezó a disminuir, y en el monte Testaccio no hay fragmentos de ánforas con sellos fechados con posterioridad a esta época. Los materiales de construcción, especialmente los mármoles más bellos, a veces se importaban por mar. Y también pequeñas cantidades de artículos de consumo de alta calidad y relativamente valiosos, incluyendo especias, tejidos y objetos de metal. (Pounds, 1987, p. 39)

La separación del imperio en Oriente y Occidente, iba a representar una cierta recuperación de la actividad comercial, sobre todo por la posición estratégica de Constantinopla, que como se verá más adelante permitió la actividad por más o menos once siglos. Con respecto a los productos que se comerciaban en Oriente:

Mas una vez patentes aquellos tránsitos para el tráfico, iban alternativamente abarcando las riquezas nativas o artificiales del Norte y del Mediodía, del Euxíno y del Mediterráneo... cuantos artefactos labraban la Europa y el Asia; el trigo de Egipto, las perlas, especias de la recóndita India, acudían en alas del viento al puerto de Constantinopla, que por largos siglos embargó el comercio del antiguo mundo. (Gibbon, 2010, p. 23)

Esta comparación entre la vuelta del comercio a las zonas del Imperio Oriental, frente al declive del mismo en Occidente, va a dar paso a los cambios estructurales en el modo de producción principalmente en las zonas de influencia del imperio en Europa central.

Si bien, la mano de obra del Imperio occidental, se sustentaba en las labores de artesanos libres, un rubro importante de comercio se relacionaba con el comercio de esclavos, funcional para los requerimientos de la administración pública y en la explotación de reservas o de las grandes propiedades. Por otro lado el Imperio Occidental nunca propició el comercio con los vecinos bárbaros, lo que tuvo una importante consecuencia en términos de la manufactura, al

no tuviesen ninguna afectación. Si el navío sufriese alguna afectación se daba por extinguido el contrato y el pago. Es interesante analizar como este mecanismo tiene relación directa con algunos contratos de tipo forward, que se dan en transacciones de comercio internacional actualmente, que buscan proteger las mercancías provenientes en tránsitos de largo recorrido. Se habla además de un conjunto de normas adjetivas acciones adjetitiae qualitatis: actio excersitoria y acto institoria. El último consistía en una acción en contra de los actos del administrador que actuaba en nombre del propietario de un negocio. Por otro lado el actio excersitoria consistía en una acción en contra de los actos de un capitán de un navío que actuaba como representante del dueño del barco. Sin embargo estas acciones aún no pueden considerarse como un derecho mercantil consolidado. 
desplazarse a zonas más apartadas, ya que estas provincias también deseaban acceder a los mismos productos que el centro imperial. Como se dijo antes, los impuestos sobre el transporte terrestre generaban productos de elevado valor, de tal manera que las provincias fueron apropiándose de técnicas de producción que abastecían sus necesidades ${ }^{7}$.

Un elemento que desencadena el declive en el comercio es la tasa impositiva sobre el transporte terrestre. El hecho ya conocido de que las tasas impositivas del Imperio de Occidente, que tenía un sistema tributario complejo y costoso y que incluía un impuesto sobre las ventas en algunas provincias, otro sobre la tierra del que estaba excluida Italia y que en zonas como la de Egipto, llegó a representar un tercio de la cosecha (Pounds, 1987, p. 47), afectó las condiciones del campesinado. Otro impuesto de captación se consideró injusto al estar exento de él los ciudadanos romanos hasta el año 212.

El pago de peajes y el elevado impuesto para el paso de mercancías por las fronteras, terminaron creando un ambiente social de inconformidad frente a las estructuras de poder, con impuestos regresivos que no tenían en cuenta las capacidades de pago de las clases populares. Esta enorme carga impositiva, mantenía según Gibbon (2010), a una extendida burocracia y al ejército que no eran productores y no contribuían al desarrollo económico del imperio.

En este contexto difícil, Diocleciano (244-211), divide el imperio en dos partes gobernadas por cuatro emperadores ${ }^{8}$. A este respecto, Pirenne (1983) considera que la Economía de este periodo comprendido entre la caída del Imperio romano y la Alta Edad Media, tiene las siguientes características 9 : existe lo que el autor denomina una ruptura del Equilibrio económico de la antigüedad, ya que el mar en el que habían nacido todas las civilizaciones antiguas (el mar interior), el mediterráneo o mare - nostrum, se constituye en una barrera más que en un elemento común:

En lo sucesivo, en vez de seguir siendo el vínculo milenario que había sido hasta entonces entre el Oriente y el Occidente, el Mediterráneo se convirtió en barrera. Si bien el Imperio bizantino, gracias a su flota de guerra, logra rechazar la ofensiva musulmana del mar Egeo, del Adriático y de las costas meridionales de Italia, en cambio todo el Mar Tirreno queda en poder de los sarracenos. (Pirenne, 1983, p. 9)

El mar y principalmente el dominio del mismo, termina realmente generando un retroceso en términos económicos, ya que deja de ser el medio por el cual se transportan las mercancías de Oriente a Occidente, retornando entonces a modos de producción basados en la actividad agrícola. Una característica de la Alta Edad Media, será entonces, la

7 Este desplazamiento en la actividad manufacturera puede encontrarse principalmente en las cerámicas en la región de la Galia y en la Germania. De igual manera en la mejor producción de tejidos en la Galia. Ver al respecto Walbank (1969).

8 El imperio de los romanos realmente no desaparece,-desaparece el de Occidente-, ya que se transforma en uno de vital trascendencia para la historia de la humanidad que lo ubica en un sendero diferente y que ha preservado para las postreras civilizaciones su tradición cultural, resultado de una mezcla de elementos griegos y romanos, enriquecidos posteriormente por los pueblos de la medialuna, reconfigurando de ésta manera las relaciones económicas y comerciales entre Oriente y Occidente.

9 Algunos autores consideran este periodo como el comprendido entre el año 476, fecha de la caída del Imperio Romano de Occidente y el año 1000 de Nuestra Era y otros consideran que va hasta la toma de Constantinopla por los turcos otomanos. 
vuelta a esta dependencia fundamental a la producción agrícola, en detrimento del comercio. Por otro lado, las continuas contradicciones entre los pueblos musulmanes y cristianos y el abrazo del cristianismo por parte de Constantino (272-337) el Grande como religión del Imperio -apuesta no sólo religiosa sino política- permite la consolidación del imperio con una ciudad reverencial, en una zona en donde en principio se carecía de agua potable, pero que resultaba ser un enclave especial en términos del tránsito desde el Mar Negro a través del estrecho del Bósforo.

Con respecto a la moneda, un hecho fundamental va a acompañar esta etapa. El abandono del numerario de oro por la numismática de plata, lo que puede apreciarse como un empobrecimiento de las condiciones generales de vida y una pérdida de riqueza para el Imperio. Sin embargo, no se debe desestimar el hecho de que las vetas de oro tuviesen importantes descensos en su explotación sin contemplar además los aumentos significativos en el tamaño de la población del imperio, variable tenida en cuenta por Pirenne y Pounds. Debido a que los niveles impositivos del imperio eran insuficientes para sostenerse, algunos emperadores como Séptimo Severo (193-211), recurrieron a prácticas como la de la devaluación de la moneda. Se cambió por ejemplo la ley de los denarios, aumentando la cantidad de metal burdo en detrimento de la cantidad de plata utilizada en cada moneda, permitiendo un mayor volumen de las mismas para poder pagar obligaciones estatales. Dicha devaluación se extiende hasta el siglo III, donde el denario prácticamente se fundía en cobre.

La acumulación de un mayor número de monedas, sin un aumento paralelo de la productividad, combinado con el reducido valor intrínseco de éstas, condujo inevitablemente al aumento de precios. Se ha dicho que hacia finales del siglo III el poder adquisitivo del denario era inferior al uno por ciento (1\%) de su valor antes del comienzo de la inflación. (Pounds, 1987, p. 49)

El tema fundamental no se sustenta en la numismática, sino en la relación entre precios para las monedas fuertes de la época, de tal manera que existían otras monedas de circulación también en cobre que tenían un menor valor que el denario, desapareciendo a la par de la depreciación del mismo. Se contaban también los denominados aurei, elaborados en oro que tenían una equivalencia de 25 denarios, que no se devaluaron y -siguiendo la Ley de Greshamse prefirió atesorarlos o fundirlos antes que cambiarlos por los denarios correspondientes. La emisión de una nueva moneda era difícil también por escases de metales preciosos.

\section{Consecuencias en la Edad Media}

Existía ya una diferencia fundamental entre un Occidente empobrecido con una élite rica que buscaba sostener sus privilegios, llevando a través de sus propias luchas a una economía de hacienda autosuficiente, en contraste con un Oriente rico que alcanzaba niveles de desarrollo mucho más notables y a un Estado que solucionó problemas claves como la inflación y la devaluación monetaria. En Occidente, esta nueva concentración de la actividad económica en la agricultura, en detrimento del comercio, tendrá como consecuencia una regresión económica durante la época carolingia; tesis de Pirenne (1983), que considera que los mercados 
locales no se constituirán más que en un espacio social, de poca importancia en la generación de riqueza. El mismo Carlomagno, prohibía a los siervos en sus dominios vagar por los mercados. La asistencia a ellos obedecía más a una necesidad de salir del campo que realmente una fuente de ganancia y de obtención de dinero ${ }^{10}$.

Por otro lado, los latifundios se consolidan sobre todo en la zona de la Galia que incluso prevalecía desde la época de Cesar. La villa gala de la época imperial, se extiende a otras zonas como el Rin, a través de la Iglesia.

La organización de los dominios es un modelo que en vano tratarán de imitar los dominios de la nobleza, pues sólo en la Iglesia se hallan hombres capaces de establecer polípticos, de llevar registros de cuentas, de calcular los ingresos y los egresos y, por lo tanto, de equilibrarlos. La Iglesia, pues, no fue sólo la gran autoridad moral de aquel tiempo, sino también un gran poder financiero. (Pirenne, 1983, p. 17)

Al ser los monjes instruidos en el conocimiento de técnicas financieras y de manejo económico, se constituían en el referente ideal para el manejo de las relaciones entre ingresos y gastos y en los depositarios del equilibrio económico-social de la época. Sin embargo, el ideal económico de la Iglesia, que se concentra en la pobreza como un valor sustancial y de origen divino y de la avaricia como pecado, da vía libre para la prohibición de la usura: Mutuum date nihil inde sperantes. El comercio incluso es tan reprobable como el dinero, ya que aparta al alma de sus fines: Homo mercator, vix aut nunquam potest Deo placere ${ }^{11}$ máxima de la iglesia arriánica que en el siglo v, indica que el mercader nunca será grato a los ojos de Dios.

Por tal razón, la actividad comercial se concentraba principalmente en el pueblo judío. En la edad media las palabras judaeus y mercator, significan lo mismo. También se les llamó radanitas, debido a sus continuos viajes, concentrando su actividad comercial en dos grandes mercados: las especias y los textiles. Resulta contradictorio que la misma Iglesia se sirviera de su actividad para la obtención del incienso básico en las celebraciones religiosas y que las telas se usaran como ornamentos en las catedrales. Lo mismo ocurre con la pimienta, que incluso llegó a constituirse en unidad de cuenta. En términos generales los judíos mercaderes trasportaban y comerciaban principalmente bienes de lujo. En la figura 1 se presenta una síntesis de las principales características de dicho periodo de acuerdo con Pirenne (1983).

10 La única feria comercial importante se encontraba en la ciudad de Saint Denys, cerca de Paris (feria de Lendit) que una vez al año congregaba a viajantes, productores y consumidores. En la mayoría de los mercados las transacciones no sobrepasaban el valor de unos pocos denarios, a estas compras se les denominaba por denerata, significando con esto su poca importancia (Pirenne, 1983, p. 15).

11 Goldschmidt, L. (1891). Universalgeschichte des Handelsrechts. Tomo I. Stuttgart, Alemania, citado en Pirenne (1983, p. 17). 
Figura 1. Características de la Edad Medía según Pirenne

Consideraciones de Pirenne (1983), con respecto a las características económicas de la Edad Media y la Antiguedad.

\begin{tabular}{cc|c|c|c|}
\hline $\begin{array}{c}\text { Ruptura del } \\
\text { equilibrio }\end{array}$ & $\begin{array}{c}\text { Presencia de los } \\
\text { sarracenos y } \\
\text { conflicto con los } \\
\text { cristianos de } \\
\text { Occidente }\end{array}$ & $\begin{array}{c}\text { Desaparición del } \\
\text { comercio en } \\
\text { Antiguedad }\end{array}$ & $\begin{array}{c}\text { Occidente } \\
\text { Presencia de } \\
\text { latifundios }\end{array}$ & $\begin{array}{c}\text { Rol de la } \\
\text { comunidad } \\
\text { Judia como } \\
\text { mercader }\end{array}$ \\
& & & & \\
\end{tabular}

Fuente: elaboración propia con base en Pirenne (1983).

\section{Características del Imperio bizantino}

Desde la fundación de la Nueva Roma, o de la ciudad de Constantinopla en el año 330, el Imperio bizantino se ha asociado principalmente para autores como Gibbon (2010) con decadencia, intriga y deslealtad, pero la caída del Imperio romano realmente significó un vasto proceso de deterioro que duró once siglos hasta la toma de la ciudad de Constantinopla en el año 1453 por los turcos-otomanos. Para quienes observaban la magnitud y esplendor de la ciudad, era, de hecho, la más magnífica de la faz de la tierra.

El Estado que se desarrolló a orillas del Bósforo y que dominó la imaginación del mundo contemporáneo hasta el siglo xII respondía a tradiciones y alianzas bien distintas. Ha sido caracterizado como una combinación de cultura griega, instituciones romanas y cristianismo, pero igualmente puede identificarse satisfactoriamente por los tres objetos de su estabilidad: la ciudad, el emperador y la fe. (Garraty y Gray, 1981, p. 262)

La ciudad de Nueva Roma se constituía en sinónimo del Estado, gracias a la añadidura de territorios en afectación directa de los antiguos territorios del Imperio de Occidente. La presencia interna de la catedral de Santa Sofía, en donde se coronaba al emperador y que constituía para la época un símbolo tan profundo como lo era la ciudad de Jerusalén o la Roma papal, eran elementos icónicos. Como se veía anteriormente, su posible caída despertaba visiones escatológicas, en tanto significaría preludio al juicio final ${ }^{12}$. Un elemento importante dentro de la caída del Imperio romano de Occidente y que va a tener una consecuencia posterior muy importante es la adopción del Cristianismo. Por ejemplo para Fisher (1958), los cristianos van a tener una visión particular, suponiendo que el fin del Imperio significaría de hecho el fin de las cosas.

Teólogos eruditos enseñaban, con plena satisfacción de las gentes ordinarias, que el mundo había entrado en su sexta y última época y que más allá del Imperio romano no había sino el Anticristo y la catástrofe de las cosas. (Fisher, 1958, p. 169)

12 No se determina a ciencia cierta si este pensamiento pudo tener alguna influencia en su toma por los musulmanes en periodos tardíos. Pero por lo menos en el mundo cristiano esta influencia sí era palpable en los escritos de los padres de la iglesia y de los santos. 
En este sentido, la restauración del imperio era una necesidad teológico-histórica. Las contradicciones entre la situación política del Imperio en términos políticos, no se compadecía de ninguna manera con el hecho de un aparente dominio a través de los funcionarios civiles y la presencia de ejércitos mercenarios en el Imperio Oriental. Estas condiciones facilitaron de hecho la aparición y desarrollo del Imperio Oriental en la ciudad de Constantinopla. El emperador era visto como un autocrator, heredero de los poderes del mismo en el Imperio romano y al asociarse con el cristianismo, se considera como su imitador; la contradicción de la fe ortodoxa se consideraba blasfemia y sacrilegio.

A lo largo de toda la historia de Bizancio, el problema de la ortodoxia dominó cualquier otro. Las mentes lógicas y excelentemente preparadas de los teólogos e intelectuales y la devoción apasionada del pueblo exigían fórmulas perfectamente definidas, aunque muy sutiles, y una sincera adhesión a las mismas. (Fisher, 1958, p. 263)

La configuración del imperio bizantino lo ha hecho verse como una especie de mezcla entre un centralismo autocrático, que es su relación directa con el mundo clásico, pero prefigurando al mismo tiempo la imagen sucesiva de las cortes absolutistas de la modernidad, diferenciándose de las monarquías jerárquicas feudalizadas de la Edad Media. Es un caso aparte en el medievo. Su singularidad se puede advertir en los siguientes aspectos:

- Una estructura urbana consolidada en cabeza principal de la ciudad de Constantinopla, que poseía grandes monumentos símbolos del Estado, así como construcciones que la protegían de los ataques de otros pueblos.

- Una complicada burocracia que debía existir por cuanto la magnitud del Estado aumentaba rápidamente en territorios que incluso realmente no llegaron a gobernarse efectivamente y que como se verá más adelante, generaron pérdidas económicas más que ingresos.

- Una economía basada en el comercio, debido a su innegable ventaja como centro geográfico.

- Un buen manejo a nivel monetario.

- Una sociedad letrada e instruida. En el plano lingüístico, por poner un ejemplo, se notaban las barreras existentes entre Oriente y Occidente: el Oriente era de lengua griega y el Occidente hablaba latín. Esto en cierto modo obligó a las élites del Imperio a tener que aprender ambos idiomas ${ }^{13}$.

El poder económico, militar y administrativo recaía en el emperador, que además adopta el título griego de basileus, quien a su vez era el patriarca de la ciudad. Su influencia religiosa también era superlativa. El gobierno netamente burocrático junto a la recopilación de las leyes romanas, fueron puntos a favor en la consolidación del Imperio, que se dividía en

13 A este respecto ver Garraty y Gray (1981, p. 266). Incluso el Código de Justiniano del siglo VI, que se redactó en latín, prefiriera el griego para su propagación en lo relacionado con la aplicación directa de sus obligaciones. 
provincias Ilamadas thémas, quienes estaban a la cabeza de los strategos, autoridades locales político-administrativas y militares. El ejército estaba bien entrenado y se constituía principalmente por una caballería denominada catafractos y por los tagmata que eran las fuerzas que defendían principalmente la ciudad de Constantinopla y tenían una mejor capacitación.

Diehl (1963) considera como una de las más importantes características de la prosperidad del Imperio, las rutas de comercio, los puertos y la influencia de la marina en la expansión económica. El imperio representaba el paso obligado de las rutas de comercio mundial, lo que le permitía centralizar el flujo de productos y bienes, para luego distribuirlos por el mediterráneo. Poseía además importantes puertos en las costas mediterráneas, entre ellos: Alejandría, Siria; los puertos de la costa de Anatolia, entre los que se encontraba Efeso, Tarsa, Atalia, Esmirna, Focea; en el sur del Mar Negro: Trebisonda y al norte el puerto de Jerson, punto de confluencia con el comercio eslavo, ruso y jázaro. En la costa de Grecia se encontraba Nauplia, Corinto, Patras, Atenas y Negroponte, importante este último por el comercio de la seda. Finalmente Durazzo, Auloma y Corú en el mar Jónico. La marina dominaba en el Mediterráneo el transporte de mercancías, pero sin lugar a dudas los más importantes serán la ciudad de Constantinopla y Tesalónica.

Para Gülersoy (1976), será característica de los siglos vı hasta el Ix, la lucha o conflicto constante contra los Ávaros, los Bulgaros, los turcos y el nuevo enemigo de oriente: Persia. A pesar de las constantes luchas, para Ostrogorsky (1963), el gobierno de Justiniano presentó una política económica que estimuló el comercio, a través de la ciudad de Constantinopla debido a que el comercio en el mar mediterráneo se encontraba en manos de griegos y sirios. Las relaciones comerciales se establecieron con pueblos como los del norte del Ponto, a los cuales exportaba tejidos, adornos, vinos y recibía a cambio cueros y esclavos. Pero la función comercial principal del gobierno se realizaba con Oriente, en especial con China e India; sin embargo, este era de carácter pasivo, sobre todo por la importación de seda. Para favorecer el intercambio, Justiniano llevó a cabo un pacto con el rey de los Hunos Ogurda, quien se había asentado en Crimea. Ogurda se vuelve cristiano tal vez por la influencia de Justiniano, siendo además una de las épocas de mayor florecimiento del Imperio bizantino, el pacto buscaba facilitar realmente el comercio.

\section{Características del Imperio en la época de Justiniano}

Justiniano es considerado por Diehl (1963), como el último emperador romano, cuyas ideas fundamentales se sustentaban en la restauración imperial y en la idea cristiana. Las reconquistas Ilevadas a cabo en África, Italia, Córcega, Cerdeña, las Baleares, una parte de España y la Galia, representan un punto de valoración positivo de su reinado, a pesar de las posteriores pérdidas. Sin embargo, padeció de un excesivo orgullo imperial y de una falta de visión con respecto a un aspecto fundamental: el imperio no podía solo extenderse a Occidente, sino que las grandes posibilidades de Oriente podrían ofrecer mejores frutos en la expansión imperial, idea que ya Teodora (su esposa), había previsto. El agotamiento del Imperio en beneficio de sus propias ambiciones sería una característica del periodo final. Para Ostrogorsky (1963), el hecho de que Justiniano tuviese un origen campesino significó un elemento civilizador ejercido por la ciudad de Constantinopla, sin dejar de lado sus características personales. Gra- 
cias a Justiniano y sus reconquistas en el Norte de África e Italia, se generó un renacimiento del comercio.

La primera parte del siglo vi, significó para la economía bizantina un periodo floreciente con respecto a Occidente. Mientras en Occidente la mayor parte del territorio estuvo afectada por invasiones, guerras civiles y disturbios, Oriente intentó resguardar las tradiciones romanas administrativas, económicas y legales. Para Laiou y Morrison (2007), en Oriente existía una mayor resistencia por parte de las instituciones y hubo una prosperidad económica que permitió librar lucha directa contra los pueblos enemigos en los Balcanes y un equilibrio frío con los sasánidas.

Sin embargo, esto no puede generalizarse para el total de las regiones. Existía una palpable diferencia en términos de prosperidad entre el Illyricum y las demás regiones del Imperio. La lucha contra los ostrogodos que se llevó a cabo entre los años 535 y 555 y la devastación de ltalia se consideran errores políticos que evitaron realmente la restauración del Imperio romano.

Este panorama ambivalente, junto con el importante significado que representó para Bizancio la recuperación de recursos desde Sicilia e Italia, va a verse truncado por una regresión económica desde la segunda mitad del siglo VI, en la que confluyeron factores como: pérdidas demográficas por la peste, que redujeron la demanda y por tanto la producción de bienes; las invasiones de eslavos y avaros en el año 560 y la reanudación del conflicto con los sasánidas en el año 572. La regresión económica fue mucho más sentida en las provincias cercanas al Danubio y en menor medida en las provincias occidentales de Italia y África; mientras esto sucedía Herakleios (610-641) lideraba la lucha contra los ataques de eslavos, avaros y persas, sin que se pudiese evitar el asedio de Constantinopla en el año 626. Para Ostrogorsky (1963), la invasión eslava a los Balcanes significó una pérdida importante en la fe de recuperación del antiguo imperio.

La estrategia de juntar la riqueza del Estado a través de los tesoros existentes y un acuerdo con el kajanato turco del Norte del Cáucaso, evitó la caída de la ciudad y la recuperación posterior de regiones de Siria, Palestina y Egipto, que habían estado en poder de los persas por 20 años aproximadamente. El actor árabe irrumpe en el año 630, reduciendo el territorio del imperio a la mitad en detrimento de la economía del Estado por cuanto ocupó las provincias de mayor riqueza ${ }^{14}$. En la primera mitad del siglo VI, hacia la década de los cincuenta la población del imperio se estimó en 30 millones de personas (Mango, 1985). Proveían una fuerte y variada mano de obra así como consumo constante de bienes. La gráfica 1 muestra la población proyectada para algunas ciudades del Imperio en el siglo VI.

14 Para Laiou y Morrison (2007), Siria, Palestina y Egipto y los antiguos territorios persas conquistados disfrutaron de una economía estable bajo el gobierno de los Omeyas, mientras que Bizancio padece un proceso de desurbanización.

tiempo\&economía

Vol. 5 N. ${ }^{\circ} 1$ - Enero - Junio de 2018

p. 71 
Gráfica 1. Población del Imperio en el siglo VI

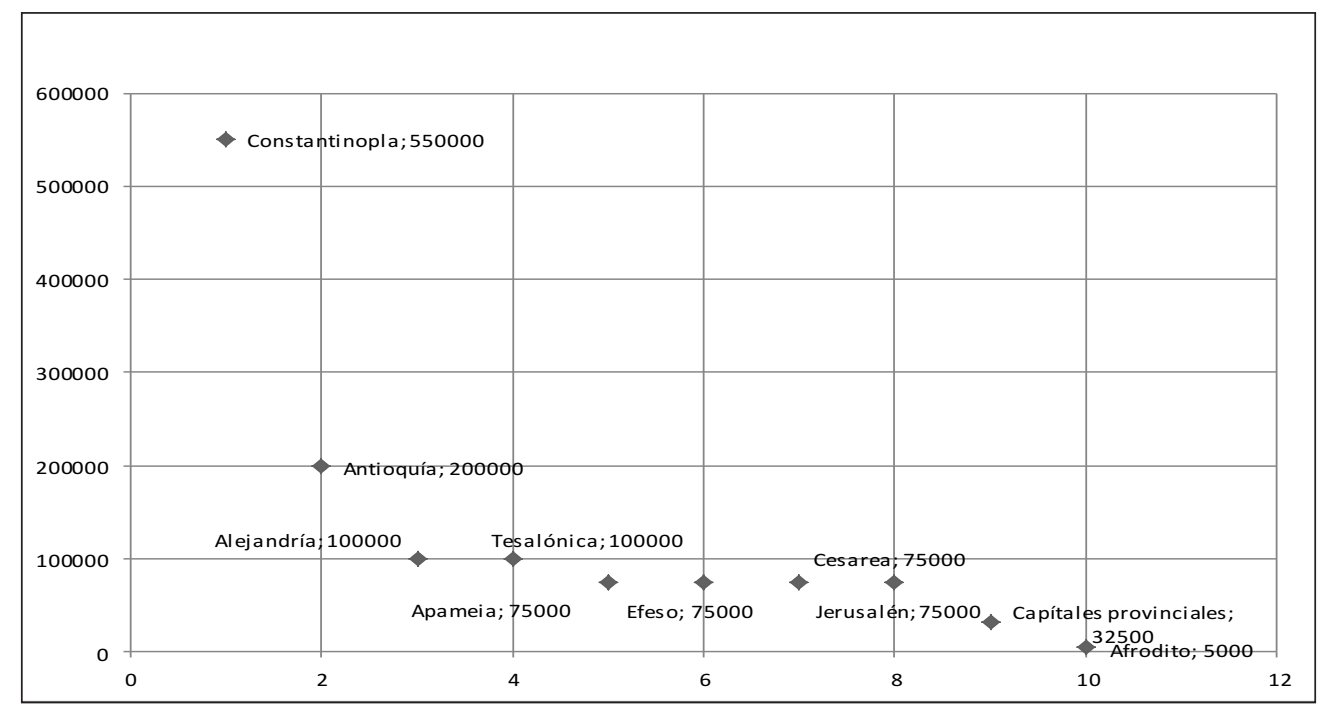

Fuente: elaboración propia con base en los datos recogidos por Laiou y Morrison (2007).

La ciudad más poblada en el mundo era Constantinopla con una proyección de 400.000 habitantes, pero nuevas proyecciones han propuesto una población de 700.000 (ver tabla 1) ${ }^{15}$. Las ciudades de Antioquía, Alejandría y Tesalónica se proyectan con una población de 100.000 habitantes; ciudades como Apameia, Efeso, Cesarea y Jerusalén, podrían tener una población probable entre 50.000 y 100.000 habitantes, las capitales provinciales poblaciones entre 15.000 y 50.000 habitantes y pueblos grandes como Afrodito cerca de 5000 habitantes. La tabla 1 muestra la proyección de habitantes por ciudad en el Imperio bizantino.

Tabla 1. Habitantes por Ciudad en el Imperio bizantino

\begin{tabular}{|cc|}
\hline Ciudad & Habitantes \\
\hline Constantinopla & $400.000-70.000^{*}$ habs \\
Antioquía & 200.000 habs \\
Alejandría & 100.000 habs \\
Tesalónica & 100.000 habs \\
Apameia & $50.000-100.000$ habs \\
Efeso & $50.000-100.000$ habs \\
Cesarea & $50.000-100.000$ habs \\
Jerusalén & $50.000-100.000$ habs \\
Capitales provinciales & $15.000-50.000$ habs \\
Afrodito & 5.000 habs \\
\hline
\end{tabular}

* La cifra de 700.000 obedece a los planteamientos de C. Zuckerman, Du village a 'l'empire: autour du registre fiscal d'Aphrodito, París, 2004, citado en Laiou y Morrison (2007).

Fuente: elaboración propia con base en los datos recogidos por Laiou y Morrison (2007).

15 Zanjando dicha discusión se propone un promedio de 550.000 habs. 
La población rural podría estimarse en más de un 90\% del total, mientras que la población urbana no alcanzaría sino el $6 \%$ del total de la población ${ }^{16}$. La población del Imperio permitía a su vez la posibilidad de abundantes factores de producción, mano de obra aunada a un gran acceso a recursos naturales. De igual manera, se tenía un acceso importante a capital fijo expresado en la producción manufacturera y agremiada principalmente en sectores como herramientas, molinos, prensas, transporte, ganado y armamento así como capital de trabajo: materias primas, metales acuñados, etc. La producción tenía un nivel de organización acorde con las estructuras materiales proveídas por el Estado: carreteras, edificios públicos y de instituciones relacionadas con la educación y el sistema judicial, lo que generó una época de bienestar económico.

En cuanto a la densidad de la población (tesis de Pirenne), esta estuvo muy cercana a la forma en que se distribuyó la población en la Edad Media. Las zonas más pobladas eran: regiones costeras y llanuras principalmente el Noreste del Peloponeso, la región de Ática y Asia Occidental Menor; Valle del Nilo, Sicilia, Creta y Chipre. En una segunda categoría tendríamos zonas como: Balcanes interiores, norte y este de Anatolia. En las zonas rurales hubo un aumento significativo de aldeas en Chipre, al interior del Líbano, el norte de Siria y las provincias de Palestina y Arabia. Un estimado del porcentaje de las zonas rurales se representa principalmente en las aldeas o granjas.

El número de sitios documentados aumenta considerablemente, pero se ha señalado el hecho de que esta multiplicación de aldeas puede haber sido de corta duración y que la prosperidad era una ilusión. No obstante, una amplia evidencia demuestra que en el este del siglo V al VII, había un pico en el número de asentamientos, de aldeas de varios cientos de habitantes o granjas y tierras marginales que fueron explotadas. Esto se puede atribuir no sólo a la seguridad, sino también en parte a un cierto cambio climático con inviernos más cálidos en el Mediterráneo septentrional y norte. (Laiou y Morrison, 2012, p. 25)

Existen registros oficiales que definen listas de ciudades y sedes episcopales del imperio que posteriormente fueron abandonadas. No es fácil, de igual manera, obtener una apreciación clara sobre la densidad urbana, ya que no se encuentran patrones de asentamientos uniformes a excepción tal vez de las ciudades ya mencionadas anteriormente. En la región de los Balcanes, parece ser que hubo un abandono importante de villas durante el siglo v. En Tracia algunas excavaciones han demostrado un aumento de asentamientos en zonas cercanas a antiguas fortalezas y en zonas de altura relativamente moderada entre 300 y 900 metros de altura ${ }^{17}$.

Las condiciones socioeconómicas y demográficas no dejan por fuera las históricas. A la muerte del emperador Anastasio en el año 518, el trono de Constantinopla pasará a manos de Justino, figura iletrada, que sin embargo dominaba el Latín al haber nacido en una aldea llamada Tauresium, región balcánica. Justino adopta y se hace cargo de su sobrino a quien

16 Proyecciones hechas con base en los datos de Laiou y Morrison (2007).

17 En la década de 540 se comenzó a percibir un alto nivel de inseguridad que obligó a la población alejarse de las zonas urbanas, principalmente por posibles ataques de pueblos extranjeros, de tal manera que algunas villas resistieron en zonas como Corinto o Mesenia, mientras que en Palestina se conformaron algunos complejos rurales que no se podían considerar en sentido estricto como villas romanas pero si como asentamientos de producción agrícola (Laiou y Morrison, 2007).

tiempo\&economía

Vol. 5 N. ${ }^{\circ} 1$ - Enero - Junio de 2018

p. 73 
educa para ser príncipe. El nombre del joven era Justiniano (483-565); se considera que incluso durante el reinado de su tío Justino, ya era el verdadero gobernante, asumiendo el poder formalmente en el año 527 a los cuarenta y cinco años, luego de la muerte de Teodorico. Antes de ello había encontrado en Teodora a su aliada principal. Teodora era la hija de un chipriota, guardián de osos del hipódromo. Había sido actriz y cortesana, combinando en su persona una situación social y un pasado propios para ofender la sensibilidad de toda persona respetable dentro del Imperio. Holmes (1905), Brehier (1969) y Bury (1923), han considerado como fundamental la influencia de Teodora en el intento de restauración del imperio llevada a cabo por Justiniano.

Por ejemplo, cuando la ciudad de Constantinopla se encontró sitiada en el año $532^{18}$, con la decisión por parte de la corte de abandonar la ciudad; la tentativa de decisión fue persuadida por Teodora ${ }^{19}$. Además de esta importante decisión Teodora acompañó en el trono al emperador por veintiún años. La influencia económica de Teodora, tendrá especial importancia en el desarrollo ulterior del imperio. Consideraba que el imperio podría obtener mayores ventajas en la medida en que pudiera enfocar sus recursos y concentración en el Asia Menor, especialmente desde Siria hasta Egipto. Verdaderamente era mucho más importante conservar el trigo egipcio que seguir arriesgándose en la reconquista de un occidente que -como se dijo anteriormente- se caracterizaba por un empobrecimiento económico. Otra insurrección se llevaría a cabo dieciocho años después en la ciudad de Constantinopla, que siguió a sublevaciones en Siria, Palestina y Egipto, que fueron desintegradas por Justiniano con prácticas crueles. Debido a estas prácticas los habitantes de las provincias dejaron de sentir afinidad con el Imperio y esperaban poder separase de él lo más pronto posible.

Un elemento importante en términos de la política llevada a cabo por Justiniano consistió en la firma de la Paz en el año 532 con Cosroes I de Persia ${ }^{20}$. Esta decisión tuvo como efecto la posibilidad del imperio de destinar sus fuerzas específicamente a la recuperación de los territorios occidentales. Para ello, se apoyó en Belisario, de quien se afirmaba poseía talentos militares incuestionables demostrados en las revueltas al interior de Constantinopla, así como en las guerras persas. Debido a sus capacidades fue enviado a África con la intención de liberar a los futuros pueblos imperiales de la influencia de los vándalos. A través de dos batallas que se llevaron a cabo cerca de la ciudad de Cartago, Belisario recuperó la influencia de la zona bajo la autoridad romana y religiosamente bajo la fe ortodoxa. Sin embargo, las amenazas sobre las tierras recobradas no desaparecieron ya que los berberiscos comenzaron hostigamientos sobre el nuevo gobierno provincial, cayendo en su poder las regiones occidentales. A pesar

18 El levantamiento del año 532 se produjo principalmente por los altísimos impuestos y por los excesos de los funciones de la burocracia imperial. Sin la ayuda de Teodora que persuadió la huida y de Belisario que al mando de un destacamento de mercenarios de origen germano atacó a los sublevados y degolló a treinta mil de ellos se logró aplastar la insurrección. Esta se conoce con el nombre de Nika que en griego quiere decir vence; grito de lucha de los insurrectos. Ver Kosminsky (1981, p. 47).

19 De quien se dice que afirmó: "pero reflexiona sí, en caso de marchar al destierro, no preferirás cada día haber muerto. Por mi parte, sostengo, con los antiguos, que la púrpura imperial es una gloriosa mortaja". Holmes, W. G. (1907). The Age of Justinian, citado en Fisher (1958, p. 171).

20 Según Ostrogorsky (1963, p. 85): en 532 Justiniano firmó una "paz eterna", con el Gran Rey Cosroes I, Anushirvan (531-79) compró, mediante el pago de tributos, la libertad de movimiento en Occidente. Pero la paz eterna se vio violada por Cosroes, quien entró en Siria, destruyó Antioquia y avanzó hasta el litoral". 
de esto, la influencia y el dominio se logró mantener, no sin grandes esfuerzos que implicaron una guerra costosa. Luego siguieron las luchas con los herejes germanos y con los godos.

En septiembre de 535, Belisario fue enviado a Sicilia con un pequeño ejército de 7500 hombres. Luego siguió una lucha de veintiocho años, durante los cuales la fortuna favoreció alternativamente a los romanos, a los godos, y por fin, de nuevo, a la causa romana (Fischer, 1958, p. 172). Cayeron en manos de Belisario Sicilia y Nápoles, encontrando luego la posibilidad de entrar en Roma, manteniéndose por un año y nueve días en contra de los godos, quienes finalmente capitularon. Vitiges rey de los godos fue tomado prisionero y Ravena ya hacía parte de las conquistas, hablándose por tanto de la Italia bizantina.

Sin embargo, los reveses sufridos en la retoma por parte de los godos de Italia a cargo de Totila con excepción de Ravena y Acona, obligaron a una paz que implicaba un gobierno por parte de Totila como súbdito del Imperio e incluso el pago de un tributo. En el año 551, Justiniano con la intención de recuperar las zonas en manos godas envía a Narses, de origen arménico al mando de un ejército de 35.000 hombres, quien derrotó a los godos. Realmente los ejércitos tanto de Belisario como de Narses, no significaron para Italia un cambio importante de mentalidad, ya que su Imperio -idea compartida por Gibbon- no era romano más que de nombre y era totalmente ajeno a los pueblos invadidos. Para Fisher, antes que realmente propiciar una reconquista del Imperio a través de la retoma de las zonas occidentales, significó un conjunto de eventos que incluyeron atrocidades entre las que se puede contar el asesinato de 300.000 adultos a manos godas y burgundias en la ciudad de Milán en el año 539, la pauperización de la vida rural y la pérdida de la supremacía de la ciudad romana.

La ciudad de Roma había perdido su influjo básico como ciudad de referencia, sus diversiones, sus baños de lujo y los espacios por los cuales era reconocida habían desaparecido.

Los negocios y el comercio se habían extinguido, y como los godos habían cortado los acueductos que habían surtido a la antigua Roma de la cantidad de agua que cualquier ciudad moderna necesitaba, el reinado de la suciedad se difundió por el mundo, sin nada que lo contrarrestase, perdido el ejemplo de la vieja Roma (Fischer, 1958, p. 174).

El deseo de reconstruir el imperio por parte de Justiniano era difícil de sostener. La recuperación de la Galia y Britania eran imposibles. Se afirma que incluso los godos habrían salvaguardado de mejor manera la herencia románica imperial ${ }^{21}$. Resulta además contradictorio que a la vez que el imperio retomaba zonas importantes de Occidente, no sin pérdida profunda de recursos y de vidas humanas ${ }^{22}$, por otro lado en la época de Justiniano se hayan tenido reveses importantes como la toma de Constantinopla por los hunos que finalmente se protegió gracias a la red de murallas; que los eslavos se hubiesen apoderado de la ciudad de

21 Fisher afirma que al ser preguntado un emisario godo advertía a Belisario: "Hemos guardado las leyes y las constituciones del Imperio tan fielmente como los emperadores del pasado. Ni Teodorico ni ninguno de sus sucesores han promulgado jamás una ley. Hemos mostrado un respeto escrupuloso a la religión de los romanos. Nunca ha sido convertido por la fuerza un italiano al arrianismo, ni los conversos godos han sido obligados a volver a su antigua fe. Hemos reservado todos los puestos de la administración civil a los italianos" (Ver Fischer, 1958, pp. 174-175).

22 Según Procopius Caesarensis (500 - 560), historiador bizantino, las muertes en Italia y África podrían calcularse en diez millones (ver Fischer, 1958, p. 176). 
Adrianópolis y que los persas hubiesen saqueado a la ciudad de Antioquia. Se derrocharon demasiados recursos en quimeras distantes que incluyeron España, cuando no era posible incluso la protección de los Balcanes frente a los ataques de las tribus bárbaras. A pesar de ello, el tamaño del imperio en la época de Justiniano aumentó considerablemente.

Los Balcanes, las islas griegas, la península de Anatolia, la reconquista de Italia, la zona sur de España, así como las zonas costeras del norte de África y sobre todo Egipto que va a tener suma importancia en términos de comercio, cuentan en la extensión alcanzada por el Imperio, que sin embargo, no alcanzó realmente la retoma de los territorios que se deseaban para la restauración del mismo, además de que el imperio había mutado significativamente en otras formas de cultura distintas, por la influencia de pueblos de las regiones orientales que ya ejercían presión sobre las ciudades principales ubicadas sobre todo en la península.

Justiniano moriría en el año 565 a la edad de ochenta y tres años, dejando realmente un imperio débil y poco romanizado; sin embargo, se reconocen como elementos importantes el manejo de la moneda, una estructura estatizada que permitió el cobro de impuestos y un control de la inflación con un favorecimiento del comercio. Baynes (2014), se refiere a este periodo como el segundo periodo o el de la dinastía justinianea que va desde el año 518 hasta el año $610^{23}$.

En lo relacionado con la cercanía o alejamiento de la ortodoxia religiosa, Justino ॥ y sus dos sucesores, mostraron un nivel de moderación, muy cercano a lo manifestado por Justiniano. Sus sucesores al ver las trasformaciones negativas - muchas de ellas a la muerte de Justinianoprobablemente no querían repetir los mismos errores ${ }^{24}$. Mauricio mantuvo el mismo comportamiento sin dejar de ser ortodoxo en el sentido de la aplicación de las políticas de relación con la iglesia pero siempre bajo el principio del dominio del Estado sobre la Iglesia.

Con su deseo de expansión del Imperio y de la restauración del mismo, Justiniano se concentró en la búsqueda de reconquistas territoriales en Italia y Sicilia, en Persia y en el Norte de África. Como se vio, cuatro grandes generales acompañaron estos proyectos bélicos: Belisario, Narses, Juan Troglita y Salomón. Sin embargo, se debe reconocer que el emperador logró importantes avances que tienen que ver por ejemplo con las estrategias de asedio y el uso de

23 Los emperadores de esta etapa histórica del Imperio son Justino el viejo, Justiniano I el Grande, Justino II, Tiberio II, Mauricio y Tracio Focas, descrito como tirano, con este último termina la dinastía de Justino. Sin lugar a dudas, será Justiniano el de mayor influencia. A pesar de que se considera que Justiniano dejó un estado de perturbación en el Imperio, su obra no se ve disminuida y seguiría en manos de sus sucesores. El primer sucesor, según Antoine (citado Brehier) fue uno de sus sobrinos, Justino Kouropalates. Después de nueve años de reinado, en 574, tuvo un ataque de locura, lo que implicó el nombramiento de un nuevo emperador. Tiberio, de origen tracio, a quien Justiniano conocía desde la infancia. Justino Il murió en octubre del año 578. Mauricio el sucesor provenía de una familia de Capadocia, quien tenía la ambición de fundar una dinastía. Las tareas que emprendieron estos sucesores de Justiniano consistieron en el restablecimiento del orden y de la situación financiera, principalmente, tal como ya se había establecido, por el excesivo pago de impuestos a los persas. Justino por ejemplo, mostró gran interés en la búsqueda de seguridad y justicia en las provincias. Tiberio y Mauricio, se destacaron el primero por considerársele un príncipe liberal y generoso, mientras que el segundo se caracterizó como guerrero, estudioso, buen administrador, pero fue bastante impopular con una pieza clave del Estado: el ejército. Sin embargo, Mauricio tuvo otro elemento negativo que se relaciona con su política de ahorro fiscal que fue bastante baja y generó desequilibrios en la balanza de pagos del Estado.

24 Justino por ejemplo convocó a los Obispos expulsados, excepto a Eutychios patriarca, pero encontró que la conciliación aún no era posible; finalmente las persecuciones continuaron luego del año 571. Ver Brehier (1969, p. 36). 
una diplomacia que permitió generar contradicciones entre los pueblos adversarios que desembocarían en luchas entre ellos.

Los longobardos fueron lanzados contra los gépidos, los avaros contra los hunos, los misioneros griegos fueron dispersados ampliamente a lo lejos entre los paganos. Pero aun así, el gobierno, que había empezado con una aureola de gloria, fue decayendo sensiblemente en el poder (Fischer, 1958, p. 176).

Se atribuye la decadencia del imperio a tres causas principales, que se resumen en la tabla 2.

Tabla 2. Causas de la decadencia del Imperio bajo Justiniano (483-565)

\begin{tabular}{|c|c|c|}
\hline Causa 1 & Causa 2 & Causa 3 \\
\hline $\begin{array}{l}\text { La gran peste de } 542 \text { que } \\
\text { generó muertes compa- } \\
\text { rables a un tercio de la } \\
\text { población. A este respec- } \\
\text { to Mc Neill (1998), consid- } \\
\text { era que Procopio realiza } \\
\text { una excelente descrip- } \\
\text { ción de la situación con } \\
\text { respecto a la pérdida de } \\
\text { vidas en este periodo } 25 \text {. }\end{array}$ & $\begin{array}{l}\text { La situación de orden } \\
\text { personal que durante las } \\
\text { últimas dos décadas de } \\
\text { vida del emperador le } \\
\text { generó problemas físicos } \\
\text { que le impidieron hacerse } \\
\text { cargo del imperio con las } \\
\text { fuerzas adecuadas. }\end{array}$ & $\begin{array}{l}\text { El peculado de la propia } \\
\text { administración que consi- } \\
\text { deraba que dos tercios de } \\
\text { los ingresos del Imperio } \\
\text { eran defraudados y no } \\
\text { llegaban la tesoro. }\end{array}$ \\
\hline
\end{tabular}

Fuente: elaboración propia sobre la base de los planteamientos de Fisher (1969).

Con respecto al primer aspecto, la peste fue bubónica había aparecido en principio en Egipto y Libia en el siglo III después de Cristo, ya siendo referenciada por un escritor médico de la época Rufus de Efesio (200), y desaparecería de nuevo hasta la época de Justiniano. En cuanto al segundo aspecto, las afectaciones que sufrió el emperador con respecto a su posibilidad de ejercer efectivamente el poder se recogen sobre todo en el cambio significativo en la personalidad y acción del emperador luego de la muerte de Teodora, suceso que parece ser, tuvo una influencia devastadora sobre su personalidad. Y finalmente, el conjunto de desfalcos que sufría el Imperio oriental, los cuales se relacionaban directamente con la excesiva burocracia.

Para Baynes (2014), existía un principio administrativo fundamental que puede explicar el surgimiento de esta burocracia estatal. Existía una separación desde la época de Constantino y Diocleciano entre la jefatura militar en manos de un dux y un gobernador civil praeses, que determinó una disminución significativa en el tamaño de las provincias. Pero ninguno de los dos podía constituirse en un peligro inminente para el emperador. El Imperio desde la época de Teodosio I (347-395), estuvo dividido en cuatro prefecturas que estaban dirigidas por un

25 Nos dirigimos a un terreno más firme volviendo a la historia de la enfermedad en las costas mediterráneas y la próxima pestilencia conspicuamente significativa llegó en el año 542 con furia intermitentemente hasta el año 750. La fuerza de una descripción larga y exacta por Procopius, se ha llamado también peste de Justiniano (542-43) puede ser identificada con confianza como bubónica, aunque todas las infecciones posteriores que aparecieron a través de las costas mediterráneas en los dos siglos siguientes no fueron necesariamente bubónicas (Mc Neill, 1998, p. 137). 
prefecto pretoriano, a su vez cada prefectura se dividía en una diócesis, denominada también vicarii, que a su vez se dividía en provincias las cuales tenían gobernadores. Se puede afirmar que la organización administrativa del Imperio había creado de hecho una separación tajante entre el poder civil y el poder militar, dando inicio a la carrera burocrática que incluso se desarrolló más allá de los límites que podía sostener el poder y el presupuesto imperial ${ }^{26}$. Si bien el mismo autor, considera que la administración era lenta y en efecto costosa, no deja de causar admiración su organización, que en últimas permitió su supervivencia. De hecho, como se verá más adelante la organización de la hacienda por ejemplo, representó un gran avance para el Imperio en términos de la recaudación de recursos.

Para Gibbon (2010), Justiniano era en realidad un emperador griego, sucesor de un vaquero latino. En varios siglos las leyes se habían acomodado durante el imperio de Occidente a las necesidades del mismo. Por esta razón, se hacía necesario un compendio de la jurisprudencia civil, que sin embargo en la práctica significó que el litigante adinerado obtendría ciertas ventajas en los procesos:

Que la ley arbitraria del juez es la tramoya principal de la tiranía; y de que las leyes de un pueblo libre deben antever y deslindar cuantos pleitos pueden suscitarse en el ejercicio de la potestad y los contratos de la industria. Pero el gobierno de Justiniano agobió), los achaques de la libertad y de la servidumbre, y el sinnúmero de leyes y el albedrío del dueño acosaban más y más a los romanos (Gibbon, 1987, p. 178).

Gibbon, desdeña del excesivo arraigo de la jurisprudencia introducida por Justiniano en detrimento de unos decretos y leyes más sencillos, lo que involucra la aparición de una tendencia burocrática, que entra en contradicción con los avances en el derecho introducidos por el emperador de oriente. Si bien, este es uno de los reconocimientos históricos hechos a Justiniano no está exento de críticas.

En términos generales, podría decirse que hay un dominio de la política de Estado sobre la influencia de la Iglesia en la época de Justiniano y de sus sucesores sin que ellos se alejaran del cristianismo ortodoxo al que había abrazado el emperador en desmedró de la filosofía clásica de origen griego y latino que había llegado a través de los musulmanes ${ }^{27}$. Fue también durante el periodo posterior a Justiniano que se presentaron relaciones internacionales entre el gobierno centralizado y la Santa Sede ${ }^{28}$.

Puede sostenerse la idea de que en la época de Justiniano, el Imperio se dividió en dos etapas: una en la que hubo un bienestar económico, con una política monetaria adecuada que re-

26 La división de las provincias en unidades más pequeñas y la constitución de la nueva jerarquía de funcionarios crearon la necesidad de un vasto servicio imperial con promociones ordenadas y regulares. Al lado de la jerarquía de funcionarios se desarrolló una jerarquía de rango con sonoros títulos. La separación de las carreras civil y militar tendió hacia la concentración y hacia la mayor eficacia y dio origen al mismo tiempo a una rígida tradición administrativa (Baynes, 2014, p. 95).

27 De hecho es Justiniano quien cierra la Escuela Platónica de Constantinopla en el año 529, considerándola un foco de paganismo y los estudios se vuelcan hacía el cristianismo.

28 Las relaciones se establecieron con el papa Gregorio Magno 590-604, pero en la época de Mauricio, se agudizó dicha relación con una ley que prohibía la entrada en funcionamiento de los monasterios. 
dujo la inflación, un gasto público expresado en obras de infraestructura y un sistema impositivo relativamente eficiente; una expansión territorial que buscaba la restauración del imperio, junto a un incentivo al gobierno sobre todo de bienes lujosos y de manufacturas con alto valor agregado. Sin embargo, una segunda etapa del mismo periodo, que podríamos denominar declive, tendría que ver con problemas relacionados con la población, reducción demográfica por la peste, lo que a su vez significó menos consumo de bienes, un excesivo aumento de la burocracia estatal y perdidas territoriales a favor de otros imperios y pueblos que avanzaban hacía Constantinopla. De hecho las nuevas rutas comerciales que evitarían al intermediario sasánida no tuvieron éxito. Las intenciones del Emperador buscaban resarcir la gloria perdida, los aspectos relacionados con el manejo monetario y el incentivo al comercio son vitales para la explicación de la economía del Imperio.

\section{Comercio exterior y manejo monetario}

Si bien el análisis central del comercio exterior se realiza sobre la base de una economía de tipo capitalista, en donde las mercancías que se ofertan en el comercio se venden a mejor precio, podemos encontrar algunos elementos comunes de análisis desde sociedades pre-capitalistas o pre-industriales: por un lado los mercaderes de la Alta Edad Media se concentraban en bienes de lujo o suntuarios que transportaban generalmente por vía terrestre. Esto implicaba vender a mejor precio y la obtención de una cuota más alta de beneficio. En el caso en que una región produjese un bien $X$, que fuese mucho más barato de producir que en otro país, se le facilitaba a este país poder vender este producto más arriba de su valor y vender esas mercancías a precios más bajos que los países competidores (Marx, 1997, p. 650). En cierto sentido, podría precisarse que las mercancías provenientes de Oriente tenían procesos de producción que implicaban una fuerza de trabajo y una cantidad de trabajo que fuese más valorada por los compradores y que no sólo se debían a una transferencia del precio por los costos de transporte. Un ejemplo claro serían las telas.

Puede suceder que este país entregue a cambio más trabajo materializado en especie del que recibe, y que, no obstante, obtenga las mercancías más baratas de lo que él podría producirlas. Lo mismo sucede con un fabricante que explota un nuevo invento antes que sus competidores y que, sin embargo, por encima del valor individual de su mercancía, es decir, valorizar como trabajo excedente la mayor productividad especifica del trabajo que ha empleado. (Marx, 1997, p. 651)

El comercio es para Marx (1974), el intermediario del valor de cambio, permitiendo el traspaso de un valor de cambio se puede hablar de la existencia de comercio. El comercio significa entonces la posibilidad de existencia independiente a través de la circulación del objeto de la producción.

El cambio de equivalentes precede (pero es tan sólo) la capa superficial de una producción que descansa sobre la apropiación del trabajo de otras personas sin cambio pero bajo la apariencia del cambio. Este sistema de cambio tiene el capital como base. Si lo consideramos aisladamente del capital, tal como aparece en la superficie, como un sistema independiente, es una mera ilusión, por más que también sea una ilusión necesaria. (Marx, 1974, p. 85)

tiempo\&economía

Vol. 5 N. ${ }^{\circ} 1$ - Enero - Junio de 2018

p. 79

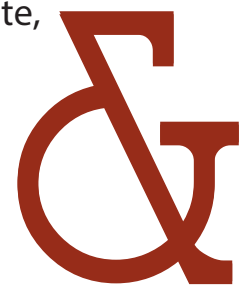


El comercio en esencia sería una actividad que no diluye la relación intrínseca entre los objetos producidos y el capital. De esta manera, se puede sostener que el comercio, que en principio, buscaría generar una ilusión de intercambio de valores, no desplaza de ninguna manera la consideración con respecto a que los bienes que se intercambian, pierdan su valor/trabajo. Pero sí se hace necesario para los mercaderes, la necesidad de obtener un medio de intercambio que permita poder encontrar esa equivalencia entre las mercancías, para asegurar la posibilidad de obtener beneficios. El significante dinero tiene aquí una importancia radical.

Históricamente, el dinero se transforma a menudo en capital en formas muy simples y evidentes. Así, el mercader pone a trabajar cierto número de hilanderos y tejedores, quienes hasta entonces se entregaban a esas actividades como ocupaciones subsidiarias en relación con sus faenas agrícolas, y convierte una ocupación secundaria en una ocupación principal, tras lo cual los tiene bajo su control y dominio como trabajadores asalariados. (Marx, 1974, p. 86)

En una siguiente fase, que supondrá la disolución del antiguo modo de producción estos artesanos, orfebres y trabajadores saldrán de su hogar a un nuevo espacio de trabajo donde se congregarán. Para Marx, el desarrollo de la manufactura será -históricamente hablando-el hito que permitirá en la producción en masa y sobre la base de un comercio marítimo y terrestre el desarrollo de un nuevo modo de producción. La manufactura no se dirigirá en principio hacía los denominados oficios urbanos, sino que tendrá como actividad básica, las ocupaciones rurales subsidiarias, por ejemplo el hilado, el tejido ${ }^{29}$.

Marx, hace énfasis en el análisis del tránsito de un modo de producción a otro, pero una característica común del paso de un modo a otro tiene que ver con el desarrollo de una economía caracterizada por la riqueza basada en la riqueza monetaria; si bien es cierto que se ha hecho énfasis en que la devaluación de la moneda fue clara causa del declive del Imperio romano de Occidente, se puede sostener que durante el imperio de Oriente la consolidación de una moneda como el sólido, representa un elemento fundamental en términos de su funcionamiento como medio de cambio, cuestión que se retomará más adelante. De Guadan y Comneno (s.f), dividen el comercio bizantino en cuatro grandes periodos con cambios fundamentales en la moneda, ver la tabla 3.

Tabla 3. Periodos del Comercio en el imperio Bizantino (483-565)

\begin{tabular}{|c|c|c|}
\hline Periodo & Extensión & Moneda \\
\hline Primer periodo & $\begin{array}{c}\text { Desde los comienzos del Imperio Bizan- } \\
\text { tino hasta el fin de la Dinastía Heracliana } \\
337-717 .\end{array}$ & De sólido pasa a Nomisma. \\
\hline Segundo periodo & $\begin{array}{c}\text { Desde León III el Isauro hasta Basilio I el } \\
\text { Macedonio 717-867. }\end{array}$ & Preponderancia del Nomisma. \\
\hline Tercer periodo & $\begin{array}{c}\text { Desde Basilio I el Macedonio hasta Alejo } \\
\text { V Murzuflo 867-1204. }\end{array}$ & Paso del Nomisma al hyperpyra. \\
\hline Último periodo & $\begin{array}{c}\text { Imperio de Nicea 1204-1258 y Dinastía } \\
\text { Paleóloga 1258-1453. }\end{array}$ & Preponderancia del hyperpyra. \\
\hline
\end{tabular}

Fuente: elaboración propia con base en los datos de De Guadan y Comneno (s.f).

29 Marx los considera aquí como de poco adiestramiento técnico y menor destreza artesanal. 
La reforma monetaria que fue llevada a cabo por Constantino, consistente en la supresión de la moneda de plata, acogiendo el monometalismo de oro, lo que permitió que se pudiera resistir a la devaluación que padeció Occidente. La unidad de moneda en la posterioridad fue el solidus áureos o nomisma cuyo peso era de cuatro gramos y de 52 a 61 centigramos. El aureus solidus podría a su vez dividirse en 72 unidades que eran equivalentes a una libra de oro que se denominó lytra. Esta era sólo una moneda de cuenta que representaba en peso 372 gramos. Cuando se valoraban grandes precios o transacciones se utilizaban lytras o kentenarias, que equivalían a cien lytras. La libra de oro equivalía a mil pesas de plata o miliaresia. El miliaresion pesaba dos gramos y representaba doce veces menos que el sueldo de oro. Este sistema monetario representó para la época un refinamiento en su uso y una reputación como medio de cambio (Andrés, 2013, p. 23).

Es el predominio de la economía monetaria lo que diferencia a Bizancio del resto del mundo medieval y lo que se instaló durante siglos en una economía natural de subsistencia. La abundancia de dinero y la generalización de la Economía monetaria siguieron siendo durante mucho tiempo las principales fuentes de vitalidad y de poder del mundo bizantino en su época primitiva...el valor de las mercancías venia siempre evaluado y, en principio, pagado en numerario, esta preponderancia monetaria no puede ser retenida sin reserva. (Andrés, 2013, p. 23)

Sin embargo, a pesar de que este factor es primordial en la explicación de Marx con relación a la superación del modo de producción no es suficiente sobre todo en la formación del capital.

Si así fuera, la antigua Roma, Bizancio, etc., hubieran concluido su historia con el trabajo libre y con el capital o, mejor dicho, hubieran pasado a una nueva historia. En ellas la disolución de las antiguas relaciones de propiedad estaba ligada también con el desarrollo de la riqueza monetaria, del comercio, etc. Sin embargo... el resultado de esta disolución no fue la industria sino el predominio del campo sobre la ciudad. (Marx, 1997, p. 77)

Para Herrin (2009), los emperadores bizantinos acuñaron monedas de oro, se podría sostener que el patrón oro fue una condición sine qua non del logró de la consolidación de la moneda del imperio. También se acuñaron monedas de plata y de cobre. Desde la época de Constantino hasta Basilio ॥, el patrón oro fue invariable, lo que en términos del cobro de los impuestos era muy importante ya que el cobro de los mismos se realizaba en monedas de oro. En la tabla 4 se presentan las equivalencias entre las diferentes monedas del imperio bizantino y otras monedas de imperios o pueblos de la época, que más allá de la numismática intenta generar una incipiente relación de términos de intercambio.

Como se había advertido anteriormente, la moneda tradicional en el primer periodo del Imperio Bizantino había sido el nomisma, el cual tenía un contenido en oro de ley de 24 quilates. Esta situación se mantuvo por siete siglos y aumentó paulatinamente su precio. El sólido tenía su equivalencia en relación con la libra romana, con una equivalencia en peso de 72 solidos por una libra romana. A su vez un sólido equivalía a 24 siliquae. Se considera que el peso de una libra romana era de 327,45 gramos y es posible que descendiera cinco gramos. El equivalente métrico del siliquia era de 189 gramos. En Grecia se utilizaba un sistema 
métrico similar. El concepto de quilate para la pureza del oro, es una unidad de masa que representa 200 miligramos, 24 quilates representa una pureza del 100\%, mientras que 18/24, representa una pureza del 75\%. Un sólido equivale a 24 quilates. Desde el año 1030, debido a la pérdida del poder adquisitivo de la moneda en el imperio bizantino seguido de un conjunto de desastres militares, se generó una disminución en el oro, que tuvo como consecuencia que en el año 1080, el contenido en oro de las monedas se redujese a 0.

Tabla 4. Equivalencias monetarias en las diferentes monedas del Imperio bizantino

\begin{tabular}{|c|c|c|}
\hline \multicolumn{2}{|c|}{ Equivalencias Monetarias } \\
\hline Fecha & Unidad & Valor \\
\hline Antes de 1092 & 1 dinar & 1 nomisma \\
$1092-1204$ & 1 hyperpyron & 0,8 nomisma \\
Después de 1092 & 1 trachy & 0,3333 hyperpyron \\
1190 & 1 Saracen besant & 0,8333 hyperpyron \\
Después 1250 & 1 gold ducat & 1 hyperpyron \\
Después 1250 & 1 silver grosso (or ducat) & 0,0833 hyperpyron \\
Después 1250 & 1 pound of grossi & 10 hyperpyra \\
Después 1250 & 1 exagion & 0,1666 hyperpyron \\
Después 1250 & 1 uncia of ducats & 1 hyperpyron \\
1300 & 1 asper barichatus & 0,0588 hyperpyron \\
1315 & 1 asper comnenatus & 0,0714 hyperpyron \\
1315 & 1 white besant & 0,2 hyperpyron \\
Después 1328 & 1 gold ducat & 24 silver Grossi \\
Después 1350 & 1 gold ducat & 2 hyperpyra \\
1375 & 1 asper barichatus & 0,1111 hyperpyron \\
1375 & 1 asper comnenatus & 0,1666 hyperpyron \\
1400 & 1 liter of small denarii & 0,5 hyperpyron \\
1402 & 14 Ottoman aspri & 1 hyperpyron \\
1405 & 1 ducat & 3 hyperpyra \\
\hline
\end{tabular}

Fuente: elaboración propia con base de los datos de Morrison y Cheynet (2002).

Después de esta debacle monetaria en el año 1092 el Emperador Alejo I Conmeno (10811118), teniendo en cuenta la drástica devaluación de la moneda en el Imperio introdujo una nueva moneda de oro el hyperpyron, que se podría traducir como súper refinado, cuya equivalencia métrica era de 4,45 gramos, pero que tenía menos quilates oro que el sólido, mientras el sólido tenía 24, el hyperpyron tenía 20,5 quilates. Como se observa, salvo contadas excepciones, el Imperio se vio en desventaja con respecto a la conversión con otras monedas, manteniendo paridades con el dinar en la primera parte del Imperio hasta el año 1092, posteriormente comienza a perder paridad con respecto a otras monedas, pero la tasa de cambio con la mayoría de ellas permite obtener beneficios considerables. Se observa como elemento característico que cerca de la caída de Constantinopla a unos 50 años, la tasa de cambio con la 
moneda otomana, el aspri, fuese tan baja de 1 hyperpyron por catorce 14 aspri, lo que demuestra en cierto sentido la fortaleza de la moneda del Imperio. La gráfica 2 muestra equivalencias con algunas de las monedas más importantes de la época.

Gráfica 2. Equivalencia del hyperpyron con otras monedas de la época

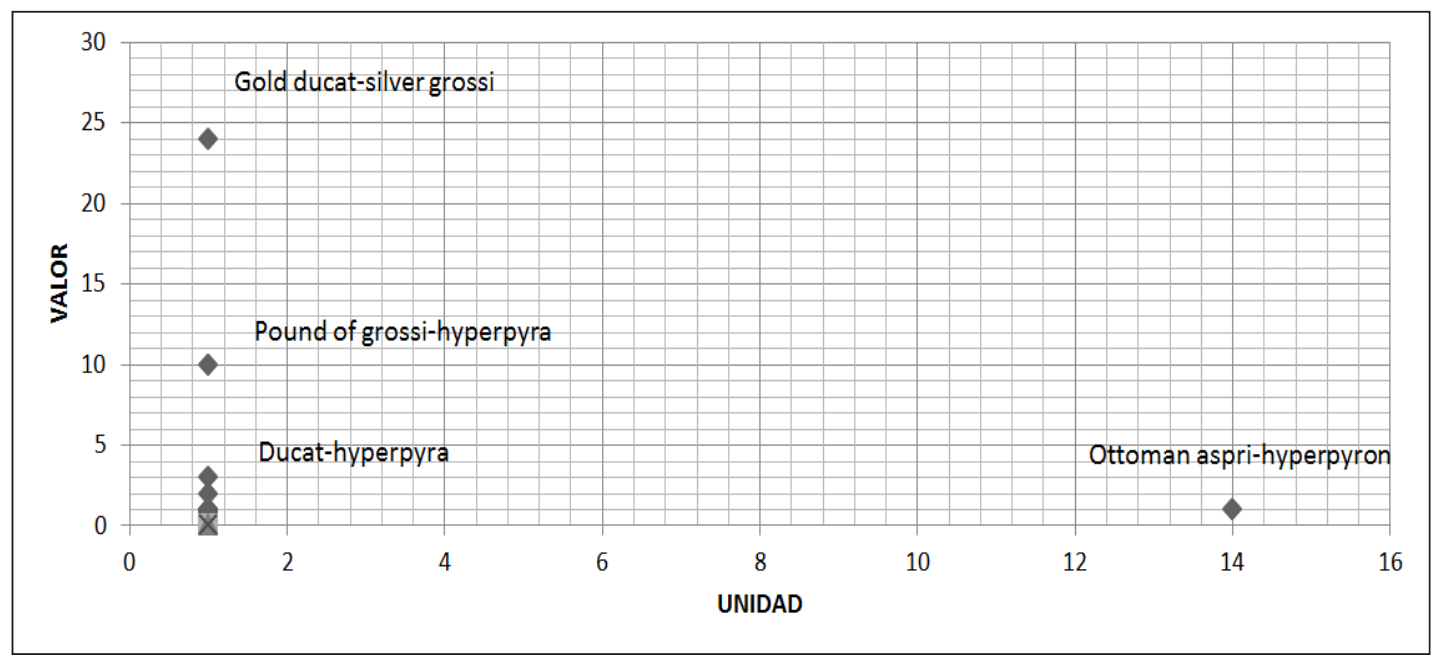

Fuente: elaboración propia con base en los datos de Morrison y Cheynet (2002).

En la gráfica podemos observar que el aspri otomano fue la moneda que más se devaluó con respecto a la unidad de cuenta del Imperio bizantino el hyperpyron, mientras que se presenta una situación inversa con respecto al ducado de oro. Si bien no es apropiado realizar una generalización con respecto al valor de las monedas en su conversión o tasa de cambio, se puede asociar esta situación con dos elementos históricos fundamentales: por un lado, el ascenso desde el siglo XII, de la ciudad-Estado de Venecia, como centro de referencia marítimo, comercial y centro de poder monetario. Por otro lado, los avances de los pueblos islámicos habían sido importantes en épocas anteriores a la toma de Constantinopla, como lo reconoce el mismo Mehmet II, pero no se alcanzaría un verdadero poder en todos los aspectos si no se lograba la toma de la ciudad ${ }^{30}$.

El manejo monetario podría definirse como uno de los elementos positivos del Imperio durante la época de Justiniano y como se observa en épocas posteriores tuvo como consecuencia

30 A este respecto, sobre las cualidades y características del Sultan ver: The Fall of Constantinople 1453. Runciman, Steve. Ed. Canto. Cambridge University Press. En el capítulo en el cual se comparan las características del joven Sultán y el Emperador Juan VIII Paleólogo afirma acerca del Sultán: But he would always be gracious, even cordial, to anyone whose scholarship he respected, and he enjoyed the company of artists. He was notoriously secretive. The unhappy events of his childhood had taught him to trust no one. It was impossible to tell what he might be thinking. He would never make himself beloved; he had no desire for popularity. But his intelligence, his energy and his determination commanded respect. No one who knew him could venture to hope that this formidable young man would ever allow himself to be deflected from the tasks that he had set himself to perform; of which the first and the greatest was the conquest of Constantinople. (Runciman, 1998, p. 59). 
una moneda relativamente fuerte frente a otras. El sustentarse en un patrón oro y en una numismática que privilegiaba este metal en la emisión fue un elemento básico para tener una moneda fuerte. El control de precios a través de edictos tuvo también una importante consecuencia en el control de la inflación que probablemente se vio bastante disminuida en el periodo de la peste por una demanda mucho más baja.

\section{La economía y el comercio bizantino}

La economía bizantina podría definirse en sus resultados y funcionamiento en grandes actividades que se extienden desde la agricultura hasta la preponderancia de la actividad comercial. Con respecto a la actividad agrícola, con la existencia de grandes propiedades latifundistas, comparte la misma naturaleza en términos de una vocación agrícola que el posterior imperio carolingio ${ }^{31}$. Generalmente la nobleza y los monasterios eran los dueños de dichos latifundios. Por otro lado, existían propiedades de menor tamaño en manos de un campesinado libre, pero que a la postre terminarían absorbidas por el sistema latifundista. En este contexto, afirma Ostrogorsky (1963), que la actividad económica en el siglo vi, va a perder influencia a pesar de la inserción de la mano de obra esclava.

El imperio Bizantino era realmente una Economía pre-industrial, de tal forma que la agricultura representaba más o menos las dos terceras partes de la Producción Nacional Bruta. Esta estimación, llevada a cabo por Laiou y Morrison (2007), da cuenta del cultivo de los siguientes productos: trigo sobre todo en Sicilia, África, Egipto, las Ilanuras de Asia Menor y Tracia, cebada, centeno, mijo y legumbres, que se consideraban parte de la dieta de los pobres, se consideraron artículos propios del autoconsumo. Con respecto al rendimiento del trigo este fue variable, con aumentos de la producción en Egipto, ya que el Valle del río Nilo facilitaba su cosecha. Los productos de fabricación interna del Imperio eran principalmente productos o bienes suntuarios: seda, tapices, orfebrería; se usaba además el marfil y los esmaltes. Si bien no existía una estructura fabril, los talleres que operaban dentro del Imperio tenían ya gran cantidad de artesanos y orfebres, que a través de la producción con un activo comercio exterior generaban un ingreso considerable para el imperio. Esta perspectiva es compartida por Marx, que consideraba a estas actividades proto - manufactureras como ocupaciones rurales subsidiarias muy importantes para el paso al nuevo modo de producción.

En comparación con el Imperio romano, De Guadan y Comneno (s.f), consideran que la principal fuente de riqueza se relacionó en muchos sentidos con un activo comercio exterior y sobre todo entre provincias. A su vez existía una organización gremial con muchos elementos comu-

31 Banaji (1999, pp. 193-194) considera, por ejemplo, que los papiros de Egipto reflejan una imagen de procesos agrícolas que provienen de operaciones de la economía rural, pero el carácter de estas actividades es muy disperso y aún poco estudiado. A consideración del autor, la razón más importante es probablemente la influencia de las concepciones minimalistas de la economía antigua, que muchas veces han impedido poder analizar a profundidad las posibles relaciones económicas que se dieron en el sector rural durante la época. Subsiste una idea de que las clases pre-capitalistas carecían de sofisticación y un cierto nivel de racionalismo característico de la economía clásica, y que los grandes terratenientes en particular eran simplemente rentistas sin interés en el trabajo, ni en los procesos de organización a un nivel más amplio de la producción. 
nes con el comercio del Imperio bizantino ${ }^{32}$. El gobierno y el Estado siempre consideraron vital el trabajo de los artesanos que conformaban gremios obligatorios.

Existía una regla: el joven de 20 años debía seguir la misma actividad de su padre, si no lo hacía perdería el derecho a la herencia ${ }^{33}$. Los esclavos que habían ganado su libertad y que obtuvieran un capital de treinta 30 libras de plata debían ser inscritos en el gremio de los descargadores, recibiendo por lo tanto ciertas compensaciones. Las exenciones recibidas y los impuestos extraordinarios como por ejemplo los navicurii (transportadores marítimos), recibían 1 sólido por cada 100 modios (cada modio equivale a 8,75 litros) transportados, con un 4\% de merma. Si se transportaba una mercancía de 10.000 modios, el impuesto territorial podría ser de 50 yugadas (medida de superficie agraria su equivalencia con el sistema métrico va de un cuarto de hectárea $2500 \mathrm{~m}^{2}$ hasta 32 hectáreas $32.000 \mathrm{~m}^{2}$ ). Existían corporaciones que recibían el impuesto en especie, las cuales recibían indemnización correspondiente a un epimetron que llegó hasta 1/40 del trigo y de la cebada y de 1/15 del vino y del tocino. Estas tasas impositivas dan cuenta de la importancia del comercio para el imperio, así como de la organización del sector productivo. El problema consecuente tenía que ver no tanto con la naturaleza del impuesto sino con el uso de los recursos recaudados.

Una expresión de la actividad comercial, según Herrin (2009) eran las ferias comerciales: las festividades que reunían celebraciones religiosas y comerciales. Un ejemplo de estas era la festividad de San Juan, que se celebraba el ocho de mayo.

En la época medieval era común que el aniversario de la muerte del santo se celebraba con una feria festiva que atraía a los mercaderes a menudo, incluso, desde largas distancias. Pese a la aparente incongruencia entre la actividad comercial y la festividad religiosa, las ferias habían pasado a estar estrechamente relacionadas con las iglesias, en especial con aquellas que contaban con imponentes reliquias que atraían a los peregrinos. (Herrin, 2009, p. 205)

Bizancio, en principio había compartido con Roma, una visión negativa con respecto al comercio que se consideró una actividad indigna. Sin embargo, las ferias que reunían a mercaderes significaban espacios que permitían al Estado el cobro de un impuesto del 10\% sobre el total de los bienes tranzados. Una feria como la reseñada por Herrin (2009), podía generar incluso 100 libras de oro en derechos arancelarios, que equivalía al pago del ejército.

La existencia de los denominados kommerkiarioi es decir de los agentes comerciales del Estado que se nombraban para cada región y que a su vez podían ejercer actividades comerciales, era garantía del orden tributario. El objetivo del Estado se dirigía a poder llevar un control sobre las exportaciones e importaciones principalmente de la seda. Cerca de Constantinopla se establecieron dos puestos aduaneros: Abidos y Hierón. La pérdida de Egipto en el conflicto

32 Según Baynes (2014), en el primer imperio o imperio de Occidente el comercio se centraba sobre todo con Oriente de donde provenían principalmente bienes de lujo que se fueron constituyendo en necesidad para el nivel de vida Romano. La diferencia entre una balanza comercial -si pudiese usarse este término- entre Europa y Asia, implicaba para el Occidente un déficit en beneficio de Oriente, lo que tenía que equilibrarse con la emisión de un numerario anual de 800.000 libras para el ajuste correspondiente de la balanza de pagos.

33 En el siglo IV, sobre todo a partir de Constantino en el año 317 se establece el principio hereditario para las profesiones libres. En este sentido tanto los fabricensces (los productores oficiales de manufacturas); los metaliarii o servidores públicos, así como los navicurii, deberían seguir también este precepto.

tiempo\&economía

Vol. 5 N. ${ }^{\circ} 1$ - Enero - Junio de 2018

p. 85 
con los persas, generó a su vez la pérdida de la importación directa de cereal en el año 619 lo que obligó a la búsqueda de nuevas rutas comerciales.

Constantinopla se constituía en el centro de comercio y las características de la ciudad como centro de reunión de mercaderes que provenían incluso de la Galia, llevó al desarrollo subsecuente de un conjunto de reglamentos que pudiesen controlar los contratos marítimos. El Derecho Marítimo Rodense, pretendía garantizar a los comerciantes un seguro sobre las mercancías en caso de pérdidas, por parte de los navíos que se contratasen para el transporte lo que generó riqueza para el gremio ${ }^{34}$. Sin embargo, el poder estatal en el recaudo dependía sobre todo de los impuestos sobre las personas y sobre la tierra. El comercio seguía considerándose por las élites imperiales como una actividad de segundo orden, de tal manera que era más importante la acumulación de capital a través de la consecución de tierras que de la riqueza obtenida del comercio. Por ejemplo, la clase senatorial no podía dedicarse al comercio y el rango social estaba representado por la posesión de grandes haciendas que en muchos casos representaban para el Estado la posibilidad de mayores recaudos. Resultaba contradictorio que la ciudad que dependía del comercio activo desdeñara de la misma actividad ${ }^{35}$.

El comercio bizantino seguía manteniendo algunos elementos claves con respecto a prohibiciones a la exportación de bienes que fuesen esenciales para el Estado: por ejemplo el fuego griego, las reservas de oro, sal, hierro, la madera para fabricación de navíos y las sedas que utilizasen el denominado purpura real, que provenía de un molusco (Murex), ya que el color rojo se consideraba específicamente propio del uso imperial. La autocracia del Estado y su deseo de establecer control económico, derivó en la redacción del Libro del Eparca, que se considera obra del emperador León VI (886-912). Con el deseo de controlar toda la producción reguló la misma para cada uno de los gremios existentes, sometiéndolos a severas condiciones que terminaron por disminuir la producción de manufacturas.

Especialmente en el periodo de Justiniano, el Imperio se mantuvo activo sobre todo con Oriente y especialmente con la China y la India. Sin embargo, como reconoce Vasiliev (1946), el Imperio Sasánida se constituyó en un imperio intermedio en el flujo de mercancías y en elemento vital en el tránsito de las mismas.

Pero el Imperio bizantino mismo no estaba en relación comercial directa con los países del Extremo Oriente, sino que el Imperio persa de los sasánidas le servía de intermediario, hallando enormes beneficios en las transacciones que practicaba con los mercaderes bizantinos. (Vasiliev, 1946, p. 93)

La existencia de la ruta marítima y de una ruta terrestre, para el tránsito de mercancías, permitió el desarrollo comercial con la utilización de caravanas que partían desde las fronteras de la China hasta la ciudad de Bukhara en el actual Uzbekistán. Las mercancías pasaban de chinos a persas quienes cumplían finalmente con el tránsito de las mismas hasta las aduanas del

34 Ya para los años 809 y 810, los dueños de navíos en la ciudad eran tan poderosos que el emperador Nicéforo I, obligó a los dueños a recibir préstamos por 12 libras oro cada uno con un interés altísimo del $16,67 \%$, si el interés regular estaba en un rango entre $4,17 \%$ y $6 \%$. (Herrin, 2009, p. 207).

35 En el siglo X, el emperador Teófilo (829-842), ordena quemar el conjunto de las mercancías de un cargamento cuando descubrió que su esposa tenía relación directa a nivel comercial con los dueños de las embarcaciones. Ver Herrín (2009, p. 208). 
imperio. Por mar, el tránsito partía desde la China hasta la isla Trapobona (Ceilán) el actual Sri Lanka, donde se hacía transbordo en buques persas que atravesaban parte del océano Indico, entraban al Golfo Pérsico hasta las desembocaduras de los Ríos Tigris y Éufrates. Navegando principalmente por el río Éufrates se llega entonces hasta las aduanas bizantinas.

Había por lo tanto una dependencia política subrogada al comercio, que tiene que ver con las relaciones entre Bizancio y Persia, que como se vio anteriormente entraron en conflicto directo durante la época de Justiniano. La importancia de los traficantes persas es esencial para el desarrollo del comercio hasta el Imperio. Sin lugar a dudas, la mercancía que tuvo un mayor flujo era la seda proveniente de la China, cuya proceso de producción en principio, siempre fue bien resguardado por los chinos. Por las guerras con los persas, los precios de la seda estuvieron propensos a especulación; de la India se importaban perfumes, especias, algodón y piedras preciosas. El deseo de Justiniano consistía en eliminar al intermediario Persa, tratando de encontrar una alternativa diferente a la bélica, de tal forma que se llegó al trazado de rutas nuevas para el comercio, lo que implicaba la necesidad de un conocimiento geográfico y topográfico que permitiese hallar alternativas a las rutas que integraban a los Sasánidas.

En la época de Justiniano, se realizaron avances importantes en la descripción geográfica que se evidencian en informes sobre las características de las cuencas del Mar Rojo y océano Índico y su relación con el comercio de productos provenientes de Oriente ${ }^{36}$. La importancia histórica de la obra de Cosmas, reside en los informes que realizó sobre las rutas comerciales y las características de los lugares de donde proceden determinadas mercancías.

Describe como testigo de vista el palacio del rey de Abisinia en la ciudad de Axum, en el reino llamado de Axum, y habla detalladamente de varias inscripciones interesantes de Nubia y de las costas del Mar Rojo. Habla también de la fauna africana e India y, sobre todo (y este es el punto más importante), nos da importantes datos sobre la isla de Ceilán (Trapobana), explicando la importancia comercial de esa isla en la Alta Edad Media. (Vasiliev, 1946, p. 94)

La importancia de Ceilán para el comercio de la época, ya se manifestaba a través del conjunto de barcos o naves que provenían de distintas partes de la India, Persia y de Etiopia y que consideraban este puerto como punto de conexión básico para el comercio. Por otro lado, la moneda bizantina alcanzaba en el comercio internacional gran reconocimiento -incluso se han encontrado monedas bizantinas en los mercados hindúes- el nomisma o sólido, era la moneda más utilizada por las naciones para el intercambio comercial. Estas características hicieron que el comercio floreciera durante la época, pero Justiniano aún tenía que enfrentarse al problema sustancial de la intermediación persa. En este sentido, se concentró en la búsqueda de la apertura de un puerto en el mar Rojo, por medio del cual pudiese tener conexión directa con la India. La apertura del puerto de Aíla, en el nordeste del golfo de Akaba, garantizaba el transporte de las mercancías que provenían desde la India, que entonces transitarían por vía terrestre a través de Palestina y Siria.

36 El texto al que se hace referencia es la Topografía o Cosmografía cristiana, escrita por Cosmas Indicopleustes, en el siglo VI. Se considera proveniente de Alejandría y fue comerciante desde su infancia. Emprendió una serie de viajes que incluyeron la descripción de zonas en la península del Sinaí, Etiopia, antigua Abisinia y tal vez la más importante: Ceilán. Su sobrenombre griego de Indicopleustes (navegante del índico), hace referencia a sus continuos viajes (Vasiliev, 1946, p. 94).

tiempo\&economía

Vol. 5 N. ${ }^{\circ} 1$ - Enero - Junio de 2018

p. 87 
Había otro puerto, el de Clisma, que se ubicaba en la zona noreste del mismo mar con conexión al mediterráneo que a la par del establecimiento de una aduana en la entrada del golfo de Akaba, en lo que actualmente se conoce como Tiran cerca al península del Sinaí, se constituiría en la piedra de lanza para la estrategia comercial del Imperio. Sin embargo, como sostiene Vasiliev (1946), el flujo de los barcos comerciales bizantinos que transitaban por el Mar Rojo era insuficiente para poder sostener un comercio activo. Debido a ello, era imperativo el poder establecer otra ruta comercial alternativa que se estableció estratégicamente con el reino Axum (con capital en Abula), cuya población eran los abisinios cristianos, que deberían suplir el papel que desempeñaban los persas como traficantes. Los abisinios cristianos deberían constituirse entonces en los corredores del comercio -principalmente de seda- entre India y Bizancio.

También cada año abandonaba Axum una expedición que marchaba al interior de África. En ella debían reunirse muchos hombres, de modo que el grupo entero contase alrededor de quinientos para poder ofrecer resistencia a los ataques de las tribus enemigas. Llevaban consigo ganado, hierro y sal. (Baynes, 2014, p.169)

Cuando estos mercaderes llegaban a su destino mataban el ganado y alzaban estacas donde ponían sus mercancías; los nativos llegaban con monedas de oro que dejaban en las estacas, si los mercaderes estaban satisfechos las tomaban y si no era así, el nativo debía poner más monedas de oro. Cuando pasaban cinco días de trueque la expedición se retiraba y volvía a su lugar de partida. Al parecer toda la expedición duraba seis meses.

\section{División del comercio en el Imperio}

Morrison (2012) considera que el comercio en el Imperio Bizantino podría dividirse en tres niveles o tipos. Un nivel local que podría caracterizarse por un tránsito de mercancías de máximo un día que incluye un radio de menos de cincuenta kilómetros por tierra. Se incluye además un rango de navegación de un día hasta un máximo de dos o tres días de tránsito terrestre. Con respecto a este aspecto se han encontrado utensilios de cocina que constituyen una aproximación de una red comercial de cincuenta kilómetros para el tránsito de mercancías incluyendo zonas como Palestina, Jerusalén, Jordania y posiblemente Amman. Los hallazgos arqueológicos de cerámica a pequeña escala en estas zonas darían cuenta de reuniones de mercaderes que realizarían actividades comerciales de corta duración.

Hay un segundo nivel regional que va desde el límite anterior hasta diez días de viaje; en términos de distancia correspondería a un radio de 100 a 300 kilómetros. Estos viajes involucran comerciantes profesionales. A nivel arqueológico, el estudio sobre la cerámica bruta no esmaltada ha generado importantes indicios sobre el comercio de este tipo por ejemplo en la zona de Amorion. En las redes de comercio regional también se deben tener en cuenta las condiciones ecológicas para la producción. Para Koder (citado por Laiou y Morrison, 2007), el radio de abastecimiento desde el interior del Imperio al sector urbano variaba según la productividad agraria de sus respectivos contextos. En igualdad de condiciones, el comercio local y regional abarcaba sobre todo los alimentos de primera necesidad y la alfarería, pero también 
podían incluir las materias primas para artesanías como el cáñamo, el lino, el cuero, el hierro, la madera, el carbón, etc.

Un tercer nivel de comercio el interregional, contemplaba la conexión entre dos regiones con un radio de 100 a 300 kilómetros. No se trata de una gran distancia pero es el tipo de tránsito, más frecuente, lo que no implica que sea necesariamente un tránsito internacional. Los intercambios regionales sí podrían incluir el paso de fronteras políticas sobre todo en el periodo bizantino medio; un ejemplo de ello es el Comercio entre Bizancio y los búlgaros o en el periodo posterior entre Cisjordania, Cilicia (ahora Cukurova) y el principado de Antioquia. Es importante señalar que para el comercio marítimo esta distinción entre lo regional y lo interregional es mucho más compleja ya que el costo inferior de esta forma de transporte no limita las cantidades como sí ocurre en el terrestre. Por otra parte, los dos niveles a menudo se combinan y las mercancías que viajan distancias largas pueden generar intercambios regionales y viceversa. Un ejemplo de esto es el comercio Intra-Adriático.

Figura 2. Niveles de Comercio Internacional en el Imperio bizantino

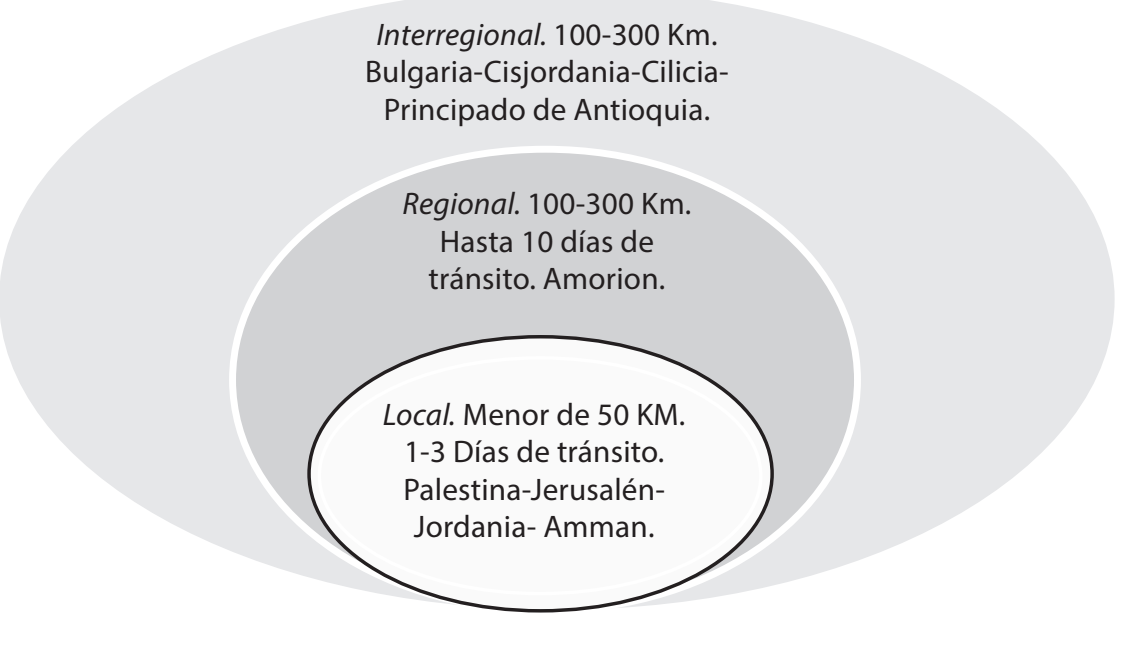

Fuente: elaboración propia con los datos de Morrison (2012).

A pesar de las intenciones de Justiniano, quienes tenían el contacto real con los habitantes de bengala eran los persas sasánidas, de tal manera que los deseos del emperador se vieron truncados por esta relación ya basada en un cierto nivel de confianza. Los intervalos de paz que se sucedieron entre el imperio Bizantino y los persas permitieron un flujo comercial con beneficios para ambos Estados, pero la seda seguía siendo transportada por persas.

Un golpe de suerte, permitió que algunos capullos de seda provenientes de la China, pudiesen ser transportados -al parecer por unos monjes o por un persa- hasta el Imperio Bizantino. Los chinos habían sido celosos en cuanto a las técnicas de fabricación de la seda. La técnica fue enseñada a los griegos y se propagó, de tal manera que ya se tenían grandes cultivos 
de moreras y se desarrolló con relativa avidez la fabricación sedera ${ }^{37}$. El centro sedero más importante fue la ciudad de Constantinopla, con otros centros importantes de fabricación en Beirut, Tiro, Antioquía y finalmente en Tebas. Existía también una fábrica en Egipto en la ciudad de Alejandría, cuya seda se llevaba a Constantinopla. Pero el elemento más importante de esta actividad económica consistía en el hecho de que era un monopolio del Estado ${ }^{38}$, siendo las sedas exportadas luego a otras zonas de Europa.

Las sedas bizantinas se exportaban a toda Europa y ornaban los palacios de los reyes occidentales y las casas particulares de los mercaderes ricos. Justino, sucesor de Justiniano, pudo mostrar la fabricación de la seda en plena actividad a un embajador turco que se hallaba en su corte (Vasiliev, 1946, p. 95).

El precio de la seda tuvo variaciones importantes durante la época del emperador Justiniano, lo que afectó el comercio principalmente en Tiro. Los comerciantes de estas ciudades debían cargar con el aumento de estos precios. Una aparente solución fue el edicto que promulgaba que no se comprara seda sobre un valor de quince solidi, pero esta prohibición hizo que la posición de los persas se endureciera y se negaran a vender, lo que arruinó el comercio de las ciudades. Los productos esenciales para el Estado seguían siendo la industria sedera, las viñas y los cultivos de aceite de oliva y el vino.

\section{Seda, vino, aceite y otros productos}

Para Ostrogorsky (1963, p. 88), la producción de la seda bizantina llegó a su apogeo sobre todo en la ciudad de Constantinopla, en Antioquía, Tiro y Beirut y en última instancia en Tebas. Para McCormick (2001), el grano y el aceite provenientes de África, parecen haber tenido influencia significativa en el comercio de la ciudad de Cartago, que se recibían en ciudades como Ostia para luego seguir hasta Constantinopla. En Alejandría se transfería desde barcazas de río hasta cargueros de alta mar. No existen muchas referencias con respecto al precio de la seda en diferentes momentos del Imperio y tampoco con relación a la época en que Justiniano gobernó. Sin embargo, en el ingente esfuerzo realizado por Morrison y Cheynet (2002) para recopilar datos de precios de la época imperial, encontramos los que se relacionan con el valor promedio de la compra de vestuario, ${ }^{39}$ ver tabla 5.

37 Para Baynes (Baynes, 2014, p. 168) este episodio ocurrió entre el año 552 y 554, donde dos monjes de Serinda o Khotan, o-en la versión de Teófanes- un monje persa de China, burló la vigilancia y llevó los capullos al Imperio. Vasiliev (1946, p. 84) afirma que Plinio tiene una versión de este hecho pero con escenario en Ceilán con dos protagonistas: dos mercaderes enviados por Claudio.

38 A partir del siglo $V$ intervino el Estado y, con el fin de suprimir la competencia, sólo permitió a los agentes imperiales la compra de la seda en la frontera, suministrándola luego a los mercaderes al precio del día. Ver Baynes (2014, p. 169).

39 Productos como el aceite y el vino eran considerados productos de consumo diario, se concentraron en regiones de África, Norte de Siria o Gaza. Para Laiou y Morrison (2007), las plantas textiles como el cáñamo o el lino se encontraban en Egipto. La morera, que crece en climas moderados y no demasiado húmedos, sirvió para la alimentación de gusanos de seda después de algún tiempo en el siglo VI en Siria y Asia Menor. 
Tabla 5. Precios promedio del vestuario en los Siglos VI y VII

\begin{tabular}{|c|c|c|}
\hline Fecha & Tipo de objeto & Precio \\
\hline Siglo VI & Vestidos de seda & 72 Sólidos \\
\hline Siglo VII & Capa & 36 Sólidos \\
\hline
\end{tabular}

Fuente: elaboración propia con los datos recopilados por Morrison y Cheynet (2002).

El precio de los vestidos de seda era significativamente alto, siendo básicamente un bien de uso suntuario. Ya se había afirmado que esta empresa constituía un bien de lujo durante el Imperio y que alcanzaba niveles de esnobismo, en la ciudad de Constantinopla y en la corte. El hecho de que el comercio de seda haya sido un monopolio del Estado que lo recibía en las fronteras del Imperio, parece ser que no tuvo mucho peso en una posible reducción del mismo. El Estado lo revendía al precio más conveniente cuando atravesaba la frontera. Por otro lado, si analizamos un producto como el vino, encontramos los datos de la tabla 6.

Tabla 6. Precios promedio del vino entre el periodo 301-613

\begin{tabular}{|c|c|c|c|c|}
\hline Fecha & Lugar & Cantidad & Precio & Precio por unidad \\
\hline 301 & Imperio & 1 xestes & 30 dinares & 0,6666 sólidos \\
\hline 340 & Egipto & 1 xestes & $\begin{array}{l}1-1,66666 \\
\text { talentos* }\end{array}$ & 0,05-0,0333 Talentos \\
\hline Siglo VI & Egipto & 1 xestes & 0,002 Sólidos & 0,04 Sólidos \\
\hline Siglo VI & Egipto & 63 angeia $=441$ xestai & 18 Quilates & 0,03125 Sólidos $=0,75$ Quilates \\
\hline Siglos VI - VII & Egipto & 1,000 xestai & 2 Sólidos-11,5 Sólidos & 0,03125 Sólidos \\
\hline Siglos VI - VII & Egipto & 2,575 xestai & 6 Solido-2 Quilates & 0,0476 Sólidos \\
\hline $606-608$ & Egipto & 525 xestai & 1 Solidos-1,5 Quilates & 0,03333 Sólidos \\
\hline 613 & Egipto & 175 xestai & 0,3333-0,25 Sólidos & 0,076923 Sólidos \\
\hline
\end{tabular}

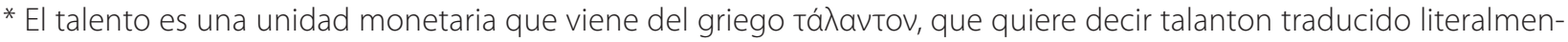
te como balanza o pesa. Se considera su verdadero origen en Babilonia ampliándose a todo el Mediterráneo en la época helenística y durante las guerras púnicas. Referencias al mismo se encuentran en el Antiguo Testamento donde se establecían equivalencias en peso de 34 Kilogramos. En el Nuevo testamento se establecía una equivalencia del talento con el dracma: 1 talento=6000 dracmas o su equivalente en plata de 21600 gramos.

Fuente: elaboración propia con los datos recopilados por Morrison y Cheynet (2002).

El vino presentaba valores mucho más bajos con respecto a los productos derivados de la seda; se observa con respecto al mismo una disminución de su valor por unidad, desde el año 301 hasta el siglo sexto. Por ejemplo, en el año 301 se pagaba por 1 Xestes4039(medio Litro), 1 dinar que equivalía a 0,6666 sólidos por unidad, mientras que en el siglo sexto se observa

40 Un xestes es una medida de líquidos utilizada y referenciada en el Nuevo testamento y que se consideraba equivalente a punto cinco (0,5) Litros. Ver: http://www.biblestudytools.com/lexicons/greek/kjv/xestes.html 
que por 1000 Xestai (equivalente a 500 Litros), se pagaron entre 2 y 11,5 sólidos. Sin tener en cuenta el tipo de vino (su calidad), ni el sitio de procedencia que probablemente acarrearía unos mayores costos, tenemos que en el año 301, si se adquirían 10 Xestai (5 Litros) de vino su costo sería de 6,6 sólidos, mientras que en el siglo sexto, si establecemos un precio promedio para las 1000 Xestai (500 Litros) de 4,75 Sólidos41,40tendremos que:

$$
\begin{aligned}
& 500 \text { Litros }=4,75 \text { Sólidos } \\
& 5 \text { Litros }=0,0475 \text { Sólidos }
\end{aligned}
$$

La diferencia entre un costo de 6,6 Sólidos para el año 301, frente a un costo de sólo 0,0475 Sólidos para el siglo vi representa una pérdida en el precio del vino de más del $600 \%$. Esto implica por un lado una mayor capacidad adquisitiva del mismo, pero como se advirtió anteriormente, es difícil poder obtener resultados significativos anteriores al siglo VI.

Otro de los productos sobre los cuales se puede rastrear un sistema de precios es el aceite, principalmente el aceite de Oliva proveniente de España y comerciado en Egipto y la ciudad de Hermópolis (ciudad griega antigua cerca de la actual ciudad de Malawii en Egipto). Morrison y Cheynet (2002), también nos ofrecen un conjunto de datos con respecto al precio del aceite (ver tabla 7).

Tabla 7. Precios promedio del Aceite Siglo VI - Año 743

\begin{tabular}{|c|c|c|c|c|}
\hline Fecha & Lugar & Cantidad & Precio & $\begin{array}{c}\text { Precio de una medida } \\
\text { de } 10 \text { Litros }\end{array}$ \\
\hline$?$ & Egipto & 45 Xestai & 1 Nomisma & 0,5 Nomisma \\
\hline Siglo VI & Egipto & $\begin{array}{c}1 \text { Kentenarion } \\
\text { (100 Litros-50 Xestai). }\end{array}$ & 4 o 5 Nomismas & 1 Nomisma \\
\hline Siglo VI & Egipto & 40 Xestai & 1 Nomisma & 0,5 Nomisma \\
\hline 579 & Egipto & 33 Xestai & 19 Quilates & 10,5 Quilates \\
\hline Siglo VII & Egipto & 80 Xestai & 40 Quilates & 9 Quilates \\
\hline Siglo VI & Hermópolis & 12 Xestai & 6 Quilates & 9 Quilates \\
\hline Siglo VI & Hermópolis & 43 Xestai & 22 Quilates & 9 Quilates \\
\hline Siglo VI & Hermópolis & 37 Xestai & 12,5 Quilates & 6 Quilates \\
\hline 743 & Constantinopla & 5 Litros & 1 Nomisma & 18 Nomismata \\
\hline
\end{tabular}

Fuente: elaboración propia con los datos recopilados por Morrison y Cheynet (2002).

La disminución en el precio del aceite, también se evidencia en el siglo sexto y séptimo, pero no en la misma proporción de perdida de precio que presenta el vino. A esto contribuyen sustancialmente el hecho de que el transito del aceite de Egipto e España se haya visto afectado por las derrotas militares subsecuentes a la época de Justiniano y que como producto implicará un mayor nivel de especialización en la producción. Antes del siglo VI -sin que se tenga una referencia real sobre la fecha exacta- el promedio del precio de este era de 45 Xestai (22,5 Litros) por 1 Nomisma, mientras que para el año 743, en la Ciudad de Constan-

41 Que es el precio promedio entre 2 Sólidos y 11,5 sólidos $X=(11,5-2) / 2=4,75$ Sólidos. 
tinopla, 10 Xestai (cinco litros), tenían el mismo precio. La pérdida del poder adquisitivo con respecto a este producto puede ser influenciada por el hecho de que el precio no sea el mismo para el resto del Imperio que en la capital, al tener en cuenta los impuestos sobre el transporte terrestre que eran bastante severos.

En la gráfica 3 se observan los datos del precio del aceite durante cuatro épocas del imperio, teniendo como unidad de cuenta el nomisma. Como vemos en un primer periodo cuya fecha se desconoce el precio de 45 Xestai (22,5 Litros), es de un nomisma; en el siglo $\mathrm{VI}$, tenemos dos datos: en un primer momento 50 Xestai que equivalen a 100 litros costaban entre 4 y 5 Nomisma ${ }^{42}$, mientras que en el mismo siglo 40 Xestai se vendían en 1 Nomisma. En la ciudad de Constantinopla en el año 743 se vendían 10 Xestai por 1 Nomisma.

Gráfica 3. Precios del Aceite de Oliva Siglo VI - Año 743

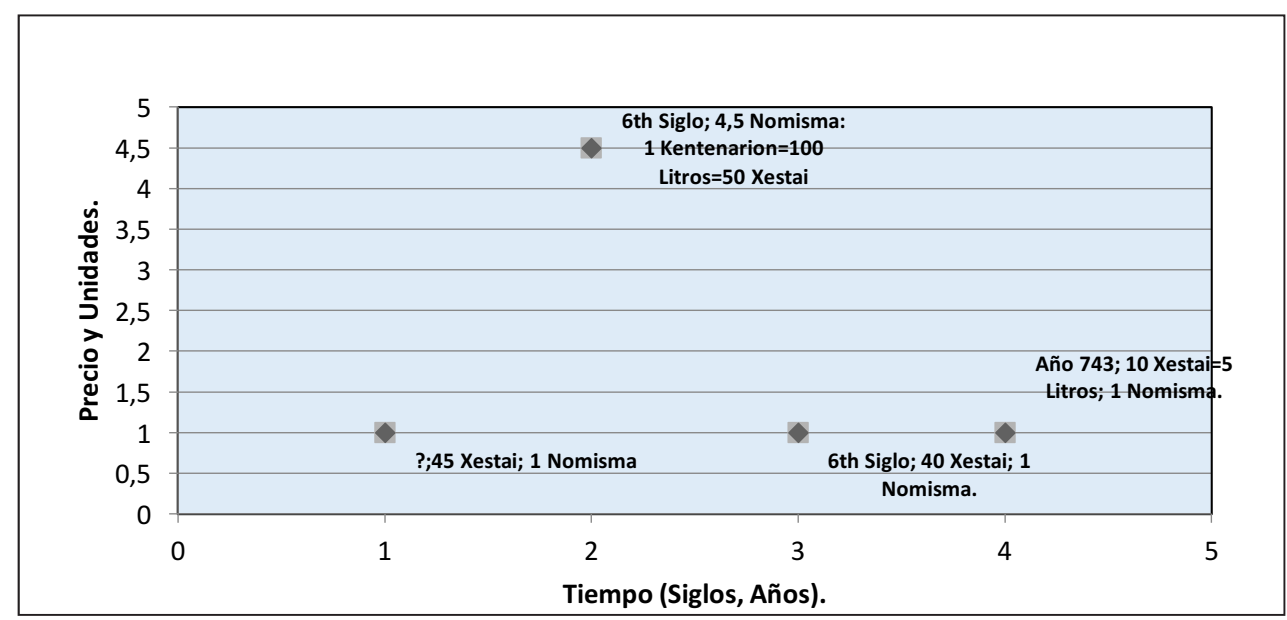

Fuente: elaboración propia con base en los datos de Morrison y Cheynet (2002).

En la gráfica 4 presentamos los precios relativos del aceite por Xestai, para los periodos referenciados anteriormente. El precio relativo más alto por Xestai correspondió al del año 743 en la Ciudad de Constantinopla (0,1 Nomisma por 1 Xestes), seguido del proveniente de Egipto en el siglo VI (0,09 Nomisma por 1 Xestes). Antes del siglo vi, se observa un precio relativo bajo de 0,022 Nomisma por 1 Xestes.

En la gráfica 5 mostramos el precio en oro y sus quilates, las unidades versus el tiempo, con respecto al aceite. En el año 579, 33 xestai tenían un costo de 19 quilates, lo que representa que un xestai vale 0,575 quilates; en el siglo vil, el precio del que se tiene referencia es de 40 quilates por 80 Xestai, pero el precio absoluto por xestai disminuiría a 0,5 quilates por Xestai; en el siglo VI en un primer periodo, se encuentra un valor de 6 quilates por 12 Xestai; el valor absoluto correspondiente sería de 0,5 quilates por xestai. En un siguiente periodo del mismo siglo se pagarán por 43 xestai, 22 quilates, lo que equivale a 0,51 quilates por xestai. En un

42 Que se promedió en 4,5 nomismas. 
último periodo del siglo vi, tendremos 12,5 quilates por 37 xestai, lo que equivale a 0,33 quilates por xestai.

Gráfica 4. Precios Relativos del Aceite por Xestai Siglo VI - Año 743

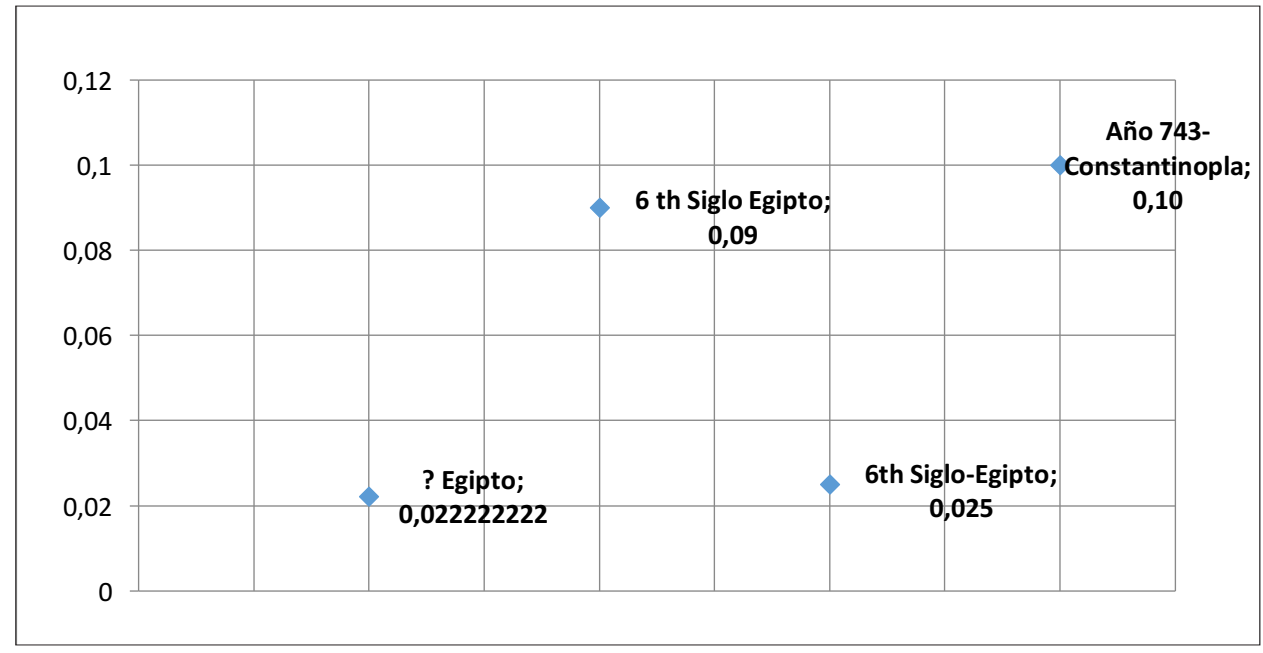

Fuente: elaboración propia con los datos recopilados por Morrison y Cheynet (2002).

Gráfica 5. Precios por quilates vs Unidades Aceite de oliva en Xestais año 579 - Siglo VII

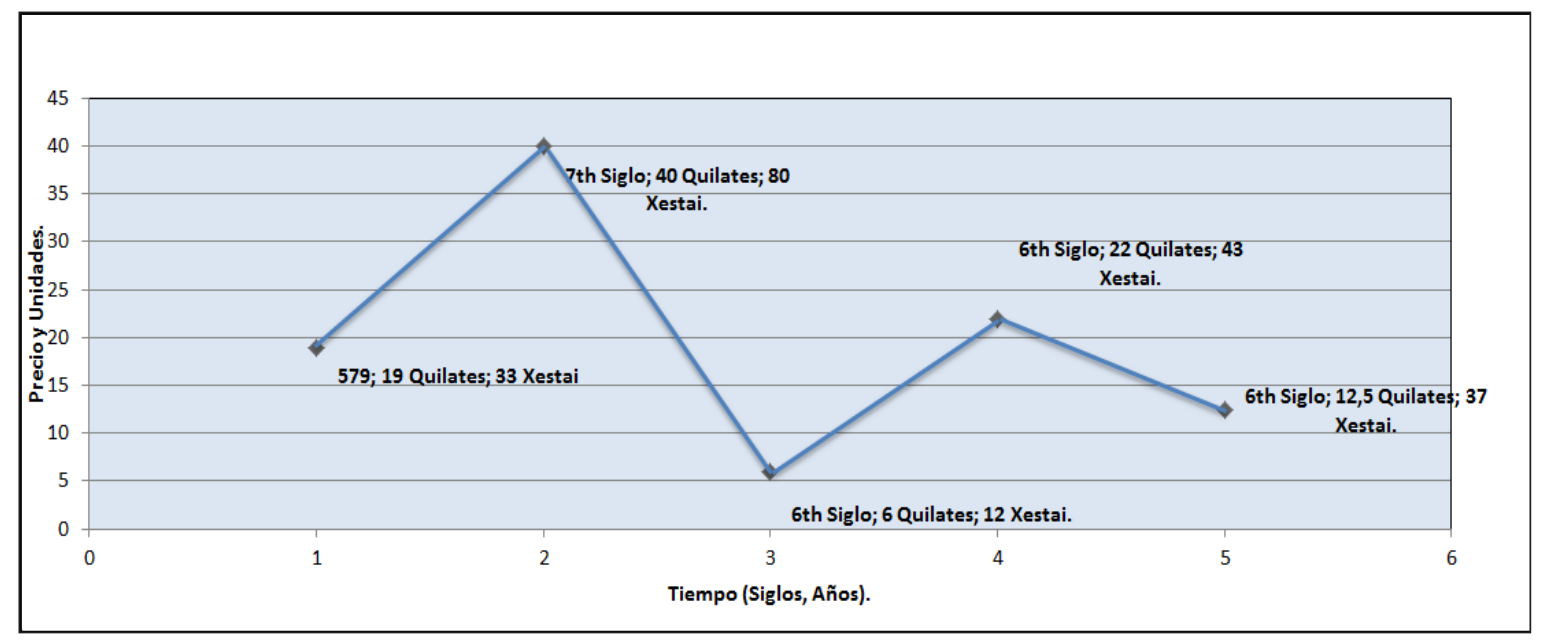

Fuente: elaboración propia con los datos recopilados por Morrison y Cheynet (2002).

En la gráfica 6 encontramos los precios relativos medidos en quilate/xestai de la producción de aceite de oliva desde el año 579 hasta el siglo VII. 
Gráfica 6. Precios Relativos Quilates/xestais Aceite de oliva año 579 - Siglo VII

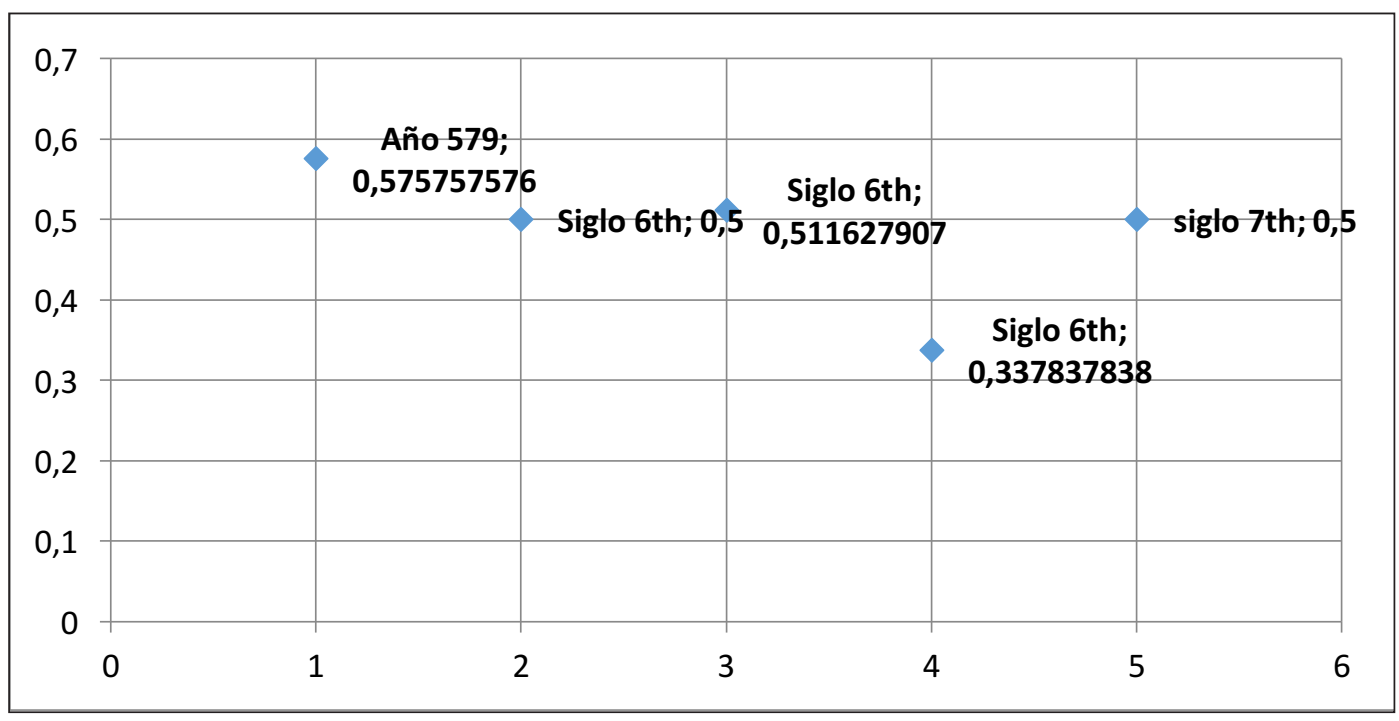

Fuente: elaboración propia con los datos recopilados por Morrison y Cheynet (2002).

Se observa una caída del precio relativo del aceite en el último periodo del siglo $\mathrm{Vl}$, a un valor de 0,33 Quilates/xestai, seguido de un aumento significativo en el siglo VII, recuperando el precio relativo que se evidenció en los periodos iniciales del siglo VI. Las razones de esta disminución pueden relacionarse con aspectos políticos que tienen que ver con pérdidas territoriales del Imperio sobre todo en España y Egipto y la imposibilidad de establecer nuevas rutas comerciales a pesar de los esfuerzos realizados por Justiniano. El nuevo aumento en el precio relativo del aceite en el siglo VII, puede asociarse con un cierto nivel de estabilidad que alcanzó el Imperio en cabeza de Heraclio (610-641), que sin embargo no pudo contener las invasiones árabes en Siria, Egipto, áfrica del Norte y Armenia, así como el hecho de que en Italia los lombardos se habían adueñado de más de la mitad de la península. El mismo Diehl (1963) considera que hasta allí el Imperio dejo de ser un imperio romano, para constituirse en un imperio netamente bizantino.

En la zona de Cesarea, Sardias y en zonas de los Balcanes, existen evidencias de la manufactura de productos de metalurgia y de cristalería. La explotación de los recursos naturales permitía la producción de madera, mármol, arcilla y metales. La madera proveía principalmente de las zonas de Dalmacia en la Grecia septentrional, el Pontus, Lycia, Creta y Chipre; esta se constituía en un elemento esencial para la fabricación naval y como combustible. El mármol provenía de Thasos y otras islas y también de Asia Menor, el imperio tenía dominio directo sobre las canteras. Con relación a los recursos minerales tenían otra distribución. En los Balcanes oro, que era controlado por el imperio a través de los denominados metallorum y los decurions municipales y luego de la iglesia en cabeza de los obispos. Generalmente, se escogían controladores de mina: procuratores metallorum para ejercer esta función. Por el lado del cobre y del hierro su utilizaban intermediarios que entregaban parte de lo extraído al Estado. La pérdida de zonas en la actual Austria (Noricum), Hungría (Pannonia), y Dalmacia implicó por lo tanto una mayor explotación de ríos y zonas acuíferas entre los siglos $\mathrm{V}$ y $\mathrm{Vl}$, principalmente en 
Tracia (Laoiu y Morrison. 2007, p. 29). De Egipto también se extraían esmeraldas, berilos, malaquita mármol, mientras que de Chipre se extraía cobre, sobre todo en la región de Vasilikos. Sin embargo, estos productos no alcanzaron la importancia comercial de los anteriormente mencionados por su poco valor agregado.

\section{Conclusiones}

Para Ostrogorsky (1963), el siglo de Justiniano no significó realmente el principio de una nueva era, sino el fin de una época agonizante. La caída de Roma, es el evento precipitador en la consolidación del imperio bizantino. Fisher (1958) distingue las siguientes características que generaron su declive: i) la presencia de una corte con visos de corrupción latente e intrigante; ii) una burocratización que se caracterizaba por su centralización excesiva; iii) una multitud de gentes que había perdido el rumbo político y que se aliaba con los partidos políticos; iv) una iglesia oscurantista con un gran poder y niveles insospechados de autoritarismo y v) un conjunto de emperadores que habían desvanecido la idea de un origen divino, para entregarse completamente a las intrigas cortesanas y a las declamaciones populares. Todo este conjunto de situaciones de orden político, económico y social condujeron a la separación del Imperio y al nacimiento del Imperio denominado bizantino.

El comercio constituyó una estructura fuerte en la economía bizantina. En esta actividad principalmente influyó la posición estratégica de la capital que controlaba la entrada al Mar Negro siendo la ruta más corta para el paso de Asía a Europa. Se generaba también un comercio importante desde otras regiones como Siria, Egipto y Palestina. Bajo el gobierno de Justiniano hubo un subsidio al sistema naval-comercial que generó un costo relativamente bajo, lo que a su vez condujo a una acumulación de riqueza del Estado a través de las tasas de tránsito de los bienes. Por otro lado, el gasto por parte del Estado en la construcción de iglesias, fortificaciones y de infraestructura ofreció empleos y una sensación de bienestar colectivo. El auge de la construcción se evidenció sobre todo en edificios estatales y religiosos como San Sergio, Santa Sofía y muchas otras iglesias que se levantaron en las capitales provinciales. Se afirma que las iglesias construidas en Arabia y Palestina llegaron a ser en promedio 160 (Laoiu y Morrison, 2007, p. 27). Se construyeron acueductos, las famosas cisternas, baños públicos, pórticos y Ágoras y se llevó a cabo un gran programa de fortificación que estuvo en cabeza principalmente de Anastasio I y de Justiniano que incluyó fortificar zonas que recorrían territorios desde los Balcanes hasta la frontera del Danubio, así como las Murallas de Tracia; en África la zona del norte de Siria incluyendo las Murallas de Dara y Antioquía.

Esta inversión, sin embargo, no se compensó con el cobro de impuestos directos sobre las personas, la tierra y el comercio y en especial bajo una segunda fase de guerras. Las compensaciones por este déficit a nivel fiscal se vieron surtidas por la reconquista de territorios gracias a campañas militares lo que aumentó la base tributaria; pero a largo plazo significó la pérdida de territorios imposibles de recuperar. Podría decirse que esta reafirmación del Estado consistía en una serie de etapas que iban desde la realización de un censo para el cobro del impuesto sobre los hogares y las personas a un proceso de determinación del nivel productivo de la tierra que implicaba saber si podía ser cultivable o no, lo que disminuía el gravamen sobre la misma además del registro de animales de tiro y granja. Realmente serán la aldea y la granja 
las que dominarán la producción agrícola, mientras que las ciudades bizantinas del Mediterráneo Oriental tendrán una influencia capital en el desarrollo económico del Imperio.

Se considera como un factor relevante de la producción nacional interna y el gasto público, que generalmente se mide en términos del pago de la burocracia estatal o el costo de su funcionamiento y de la infraestructura. Se puede considerar como significativo el gasto del Estado para garantizar seguridad, agua potable y de manera muy especial de espacios religiosos para la contemplación y la oración ${ }^{43}$. Este gasto del Estado significa, en términos económicos, un aumento en el nivel de vida y riqueza, el desarrollo de fuerzas productivas que se representan en el conjunto de artesanos y trabajadores que fueron contratados para llevar cabo estas construcciones y por ende un mejoramiento en el nivel de la demanda interna que permitía a los habitantes del imperio poder acceder a bienes de consumo.

Estos bienes -entre los que se analizaron la seda, el vino y el aceite-provenientes en su gran mayoría de China e India, en el caso de los suntuarios y de Siria y Egipto en el caso de bienes básicos, permitieron un flujo comercial importante en el primer periodo del Imperio bajo Justiniano que representó mayores niveles de recaudo y de gasto, a su vez que de unos niveles mayores de consumo. Sin embargo, en una segunda etapa, el declive del Imperio se puede atribuir a los excesivos gastos gubernamentales en la restauración del Imperio en Occidente, por pagos y pérdidas significativas en las guerras llevadas a cabo y la excesiva burocracia, así como la imposibilidad de abrir nuevas rutas comerciales que impidieran por un lado no tener como intermediarios comerciales a los sasánidas y por otro evitar la ya notoria influencia del pueblo musulmán.

El poder gubernativo había perdido mucho de su autoridad desde el fracaso de la restauración justinianea. Como reacción natural contra el absolutismo justinianeo, fue creciendo no sólo la importancia política del Senado, sino también el afán de libertad entre el pueblo (Ostrogorsky, 1963, p. 95).

Finalmente, el manejo de la moneda se debe analizar como un ejemplo de un conjunto de medidas que permitieron contrarrestar aspectos como la inflación, permitiendo un poder adquisitivo estable, que se manifestó en la intención de que el sólidi no perdiera su valor de oro para sostenerse como una unidad de cuenta fuerte, tal y como lo muestran los datos de tasa cambio frente a otras monedas. Estos aspectos revelan la importancia que tuvo un decidido enfoque hacia el comercio y un manejo prudente de la política monetario durante la época de Justiniano I.

\section{Referencias}

Andrés, J. (2013). Notas sobre la regulación jurídica del comercio internacional en el Imperio Bizantino. Revista electrónica Historia del Orbis Terrarum Edición y Revisión Editorial de Estudios Medievales, 11, 17-49.

43 Más de un millón de monedas de oro (solidi) se gastaron en Santa Sofía. Por otro lado, Julianus Argentarius, el Banquero, gastó 26.000 solidi en San Vitale en Ravenna. Ver Laiou \& Morrison (2007, p. 27). 
Banaji, J. (1999). Agrarian History and the Labour Organisation of Byzantine Larges Estates. In: Proceedings of the British Academy, 96. The British Academy, pp. 193-216.

Baynes, N. (2014). El imperio Bizantino. México: Fondo de Cultura Económica.

Bergier, J. (1973). Situación y problemas actuales de la Historia Económica. Cuadernillos de Historia Social y Económica, 6.

Bergier, J. (1963). Métodos actuales y Objetivos de la Historia Económica. Cuadernos de Historia Social y Económica, 3.

Biblioteca Jurídica Virtual del Instituto de Investigaciones Jurídicas de la UNAM. Recuperado de http//biblio.juridicas.unam.mx

Brehier, L. (1969). Le monde Byzantin: vie et mort de Byzance. Collection l'Évolution de l'Humanité Éditions Albin Michel, 1946 et 1969, Paris.

Bury, J. (1923). History of the later Roman Empire, 2 v., Londres, Selected essays, Cambridge, 1930.

De Guadan M, y Comneno, L. (s.f). Ensayo sobre la evolución comercial y monetaria en Byzancio. Recuperado de http://ler.letras.up.pt/uploads/ficheiros/10885.pdf

Diehl, C. (1963). Grandeza y Servidumbre de Bizancio. Madrid: Espasa-Calpe S.A.

Duncan, J. R. (1994). Money and Government in the Roman Empire. Ed. Cambridge University Press. Recuperado de https://books.google.com.co/books?id=nUtzJnjAic0C\&pg=PA58\&l$p g=P A 58 \& d q=x e s t a i+m o n e y \&$ source $=$ bl\&ots=MjMfN5fT3M\&sig=TW3qNZvDGIpYLiLZyONR8yBpkuQ\&hl=es\&sa=X\&ved=0ahUKEwiN6tT95IDRAhUG4WMKHXKMCwcQ6AEIHDAA\#v=onepage \&q\&f=false

Fisher, H. (1958). Historia de Europa. Tomo I. Buenos Aires: Editorial Sudamericana.

Garraty, J y Gay, P. (1981). El Mundo Medieval. Historia Universal 2. Ed. Barcelona: Bruguera.

Gibbon, E. (2010). Historia de la decadencia y caída del Imperio romano. Madrid: Ed. De bolsillo.

Gülersoy, C. (1976). A Guide to Istanbul. Yenilik Basimevi. Istanbul. Turkey.

Hendy, M. (1985). Studies in the Byzantine Monetary Economy c. 300-1450. Cambridge University Press. Recuperado de https://books.google.com.co/books?id=zLvhlphg8zwC\&p$\mathrm{g}=\mathrm{PA} 198 \& \mathrm{lpg}=\mathrm{PA} 198 \& \mathrm{dq}=$ Kentenarion $\&$ source $=$ bl\&ots $=$ YHeoUZCOKc\&sig=znB2ZfbzQ_OLbBc4nhy1cie4HY8\&hl=es\&sa=X\&ved=0ahUKEwi0klaS_YDRAhUm64MKHWOLBEs$\mathrm{Q} 6 A$ EIMDAD\# $\mathrm{v}=$ onepage $\& \mathrm{q} \& \mathrm{f}=$ false

Herrin, J. (2009). Bizancio. El Imperio que hizo posible la Europa moderna. Barcelona: Ed. Debate.

Holmes, W. G. (1907). The Age of Justinian and Theodora. A history of the Sixth Century A.D. Volume I and II. Ed. George Bell and Sons. London.

Kosminsky, A. (1981). Historia de la Edad Media. Bogotá: Ed. Norte.

Laiou, A y Morrison, C. (2007). The Byzantine Economy. Cambridge Medieval Textbooks. Cambridge University Press.

Mango, C. (1985). Le developpement urbain de Constantinople, IVe-VIle siecle. Paris. 
Marx, K. (1974). Formaciones económicas precapitalistas. Medellín: Oveja Negra.

Marx, K. (1997). El Capital. Barcelona: Ed. Folio.

Morrison, C (2012). Trade and Markets in Byzantium. Dumbarton Oaks Byzantine Symposia and Colloquia. Trustees for Harvard University, Washington, D.C.

McCormick, M. (2001). Origins of the European Economy communications and Commerce A.D. 300-900. Cambridge University Press.

Mc Neill, W. (1998). Plagues and Peoples. New York: An Anchor Book.

Ostrogorsky, G. (1963). Historia del Estado Bizantino. Madrid: Ed. Akal.

Pacaut, M. (1957). Histoire. Le Moyen Age, de 987 a 1492. Fernand Nathan, Editeur. Paris. VI Edicion. Francia.

Pirenne, H. (1983). Historia Económica y Social de la Edad Media. México: Fondo de Cultura Económica.

Pounds, N. (1987). Historia Económica de la Europa Medieval. Barcelona Crítica.

Procopio de Cesarea. (2007). Historia de las guerras Libros VII - VIII Guerra gótica. Vol. 3. Barcelona: Gredos.

Runciman, S. (1998). The Fall of Constantinople 1453. Cambridge: Cambridge University Press.

Stone, M \& Ervine, R. (2000). The Armenia Texts of Epiphanius of Salamis De Mensuris et Poderibus. Corpus scriptorum christianorum orientalium. Universidad Católica Americana- Universidad Católica de Lovaina. Vol 583. Tomo 105. Recuperado de https://books.google.com. $\mathrm{co} /$ books? id=v_2uuBxSL4gC\&pg=PA37\&lpg=PA37\&dq=xestai\&source=bl\&ots=xXq8BMpw1 k\&sig=TSu14s8aQy3bQ59w_AJABq0UPao\&hl=es\&sa=X\&ved=0ahUKEwiL8fTs6IDRAhXkj1QKHUpXCYoQ6AEIGzAA\#v=onepage\&q\&f=false

Vasiliev, A. (1946). Historia del Imperio Bizantino. Tomo I y II. Barcelona: J. Gill.

Walbank, F. (1969). The Awful Revolution (pp 47-54). Liverpool Press.

Wallerstein, I. (2006). Abrir las Ciencias Sociales. México: Fondo de Cultura Económica. 